\title{
The 20-minute city: an equity analysis of Liverpool City Region
}

\author{
Alessia Calafiore ${ }^{\mathbf{1}}$, Richard Dunning ${ }^{\mathbf{1}}$, Alex Nurse ${ }^{\mathbf{1}}$, Alex Singleton ${ }^{\mathbf{1}}$ \\ ${ }^{1}$ Department of Geography and Planning, University of Liverpool, Liverpool, UK \\ Email: \\ A.calafiore@liverpool.ac.uk
}

Received 01/04/2021

Accepted for publication 05/11/2021

Available online 04/12/2021

Cite as: Calafiore, Alessia, Richard Dunning, Alex Nurse, and Alex Singleton. "The 20-minute city: An equity analysis of Liverpool City Region." Transportation Research Part D: Transport and Environment 102 (2022): 103111.

DOI: https://doi.org/10.1016/j.trd.2021.103111

\begin{abstract}
The 20-minute city has become a popular urban planning policy to support low-transport neighbourhoods. Whilst meeting residents' needs in local neighbourhoods is not a new concept, urban and transportation planners are increasingly being tasked with re-structuring transport and public services to facilitate people 'living locally'. The existence of a 20-minute city is seen as a signifier of urban success and has taken on political acknowledgement through the pandemic, yet existing spatial inequalities contribute to the daunting headwinds in making active travel support an equitable city. In this paper, we provide a novel approach to identify where 20 -minute neighbourhoods might exist within a large city region and assess how their existence aligns with socio-spatial inequalities.
\end{abstract}

Keywords: accessibility, social equity, transportation planning, 20-minute city

\section{Introduction}

Accessibility to key employment, education and health services is paramount to the equity of cities. Ethnic minorities (Hu, 2019), lower-economic groups (Pan et al., 2020) and other groups, in many cases intersectionally experienced, have disadvantageous access to key services and employment. Improving access to transportation is, thus, often identified as a key planning requirement to enhance justice in the city (Martens, 2016, Pereira, 2016), both horizontally and vertically (Litman, 2002). Distributional analysis can reveal transportation justice and given the availability of analytical tools it is imperative to assess plans to amend urban accessibilities through equity analysis (Bills and Walker, 2017).

In retrospect 2020 may be a critical juncture in sustainable urban transport planning as COVID-19 impacts on residents' and politicians' perceptions (Nurse and Dunning, 2020). The pandemic has caused political interest to turn to active travel as the subject, and the neighbourhood as the spatial scale with the repurposing of road space (Dunning and Nurse, 2020; Frank et al., 2021). Through this period there has been a significant resurgence in policy makers' interest in the concept of the 15- or 20-minute city (Pozoukidou and Chatziyiannaki, 2021). The 15-minute city, widely acknowledged as created by Carlos Moreno, re-works several ideas from earlier planning practice, and has been extended to the larger 20-minute city concept (Capasso Da Silva et al., 2020), seeks to bring core services and residents together in neighbourhoods that are accessible within a 10-minute walk from home to service. The concept's popularity, exemplified by Parisian mayor Anne Hidalgo's policy interest, arises from its support for a range of urban policy goals, including reducing car dependence and carbon emissions, supporting local businesses, and supporting mental health through increased social interactions (Reid, 2020). As 
urban planning seeks to re-align services and transportation networks to facilitate the 20-minute city, the key question from a transportation equity perspective is whether these neighbourhoods equally support a city's population.

This paper is a novel exploration of equity and the 20-minute city concept. It explores Liverpool City Region as a large metropolitan region with diverse existing inequalities and services accessibility. We provide a new method to identify areas that approximate neighbourhoods in the 20-minute city, an approach that could be replicated elsewhere. We then explore how existing inequalities across Liverpool City Region are driven by socio-economic factors before discussing key environmental considerations if the 20-minute city is to respond to its sustainable ideals. We next turn our attention to the literature on the 20 -minute city before introducing Liverpool City Region as a case study. The methods to identify 20-minute neighbourhoods are described with the equity analysis approach, before presenting the analysis results. We then offer critical points for discussion in response to the framing of contemporary arguments for the 20-minute city and summarise our argument in the conclusion.

\section{Literature Review}

\subsection{The 20-minute city}

At its heart, the idea of the 20-minute city is a simple one: that most basic needs can be met within a 20-minute round trip from the home (Sustrans, 2020). This is often considered to be a 10-minute walk, although some definitions have expanded this to include other active travel methods (e.g., cycling), and even other sustainable modes (e.g., public transport) (Stanley and Davis, 2015). The 20-minute city sits at the nexus of several concurrent debates in urban development and can be seen as the latest manifestation of planning approaches such as New Urbanism (Iravani \& Rao, 2020) and Smart Growth (Edwards \& Haines, 2007); one in which the focus on human-scale design meets accessibility-oriented planning (Papa, 2020, Deboosere, 2018). So far, the 20- or 15- minute city concept has been discussed by scholars emphasising slightly different but interrelated facets (Dunning et al., 2021).

The advantages of active travel and the 20-minute city have variously been analysed concerning a range of urban planning challenges, such as sustainability planning for climate change mitigation (Capasso a Silva, 2020), healthy life planning through the prevention of non-communicable diseases (Weng et al., 2019), and planning the Smart City (e.g. Moreno et al, 2021). Approaches have varied from walkability scores (Carr et al., 2010, Shashank and Schuurmann, 2019), to cycling mobility (McNeil, 2011) and mobility choices (Graells-Garrido et al., 2021).

Whilst the idea of a 15- or 20-minute city builds upon diverse planning concepts, it is noticeable that it is gaining significant traction as consolidating concept (Dunning et al., 2021). Therefore, while there is consensus that, through such a planning approach city vehicular travel should be minimised and it should be easier to get around neighbourhoods by walking or cycling, it is yet to be clarified precisely what should be within 10 minutes' reach. Some have attempted to establish minimum standards in a way that engages with whole life living within neighbourhoods. The classifications vary in the detailed list of amenities, but generally agree on certain broad categories of services, with education, healthcare, food-related services being the most common. As broadly put by the C40 Cities Climate Change Leadership Group (2021), in a 15-minute city "residents of every neighbourhood have easy access to goods and services, particularly groceries, fresh food and healthcare". Sustrans (2020), a UK based charity that promotes sustainable transport choices, have also suggested a set of destinations within the category of food, education, health services, financial services, employment, public open space, entertainment and transport provision. Moreno et al. (2021), highlight the need for six urban functions in a 15-minute city: (a) living, (b) working, (c) commerce, (d) healthcare, (e) education and (f) entertainment. Meanwhile, O' Gorman \& DillonRobinson (2021) envisioned the development of 20-minute neighbourhoods in Scotland that guarantee access to places across four dimensions: movement (i.e. public transport, active travel), civic (i.e. heritage assets), stewardship (i.e. community organization, resident association), resources (i.e. supermarket, health facilities, job opportunities), spaces (i.e. parks, sports complex). Grodach \& Harper (2019) identify the community infrastructures required by geographical level, by their district level definition (with a catchment size up to 800 meters which is the average distance walked in 10 minutes) the infrastructures expected to be present span from green spaces/parks, education and religious institutions, sports facilities, local shops, post offices and health centres. Wang et al. (2019) and Capasso Da Silva et al.(2020) selected the amenities based on inputs from city dwellers with slightly different results - i.e. in Capasso Da Silva et al. (2020) faith-based services are included while Wang et al. (2019) included elderly care and transport provision - which converge around food related, commercial, health, recreational and educational services. 
In this study, we select the relevant amenities based on the most common categories proposed in the existing literature presented above and data availability (see Section 3.1). However, we voluntarily focus on non-work-related amenities, acknowledging the extent to which home-based work during the COVID-19 pandemic has changed the role of commuting in people daily life and would require further investigation.

Despite a lack of well-established approaches to planning these interventions so far, we note that the 20-minute city general principles have received widespread policy attention, and we can see examples emerging which seek to put the ideas discussed above into practice. Here we note that the 20 -minute city has significant overlap with other similar concepts notably the 'low traffic' and 'liveable' neighbourhood (Nieuwenhuijsen and Khreis, 2019). Beyond well-trodden exemplars (i.e., the Netherlands, Denmark), these ideas have begun to emerge at greater speed through the 2010s. Melbourne was amongst the first to formally recognise the 20-minute city in its longer-term transport strategy (Stanley and Davis, 2015), whilst we have also seen many schemes emerge at the project level. One notable example is the London Borough of Waltham Forest, whose 'Mini-Holland' scheme saw the implementation of traffic calming measures, and within one year of its implementation, resulted in residents being $24 \%$ more likely to cycle, and an increase in the average weekly active travel time of residents by 41 minutes (Aldred et al, 2019). Elsewhere, the Mayor of Paris, Anne Hidalgo, made the 20-minute city a central plank of her successful 2020 re-election campaign bringing the most high-profile attention to the idea thus far (Reid, 2020). This process has been further accelerated through the COVID-19 pandemic as cities across the Global North and South have recognised the value of active travel for exercise, travel against the restraints of a restricted public transport network, and an increased desire/need to stay local in the face of national restrictions on movement (Nurse and Dunning, 2020).

In the case of the UK, these approaches have also been aided by a government programme designed to reallocate street space to active travel in the face of the pandemic (DFT, 2020). Here, several cities - most notably London (particularly, the boroughs of Hackney), Leeds and Oxford have brought forward plans for Low Traffic Neighbourhoods. In these cases, tactical urbanism (Mould, 2014) has been deployed in the form of strategic point closures which have, in effect, closed off vehicular through traffic. The effect has been to create quieter streets for residents, whilst simultaneously expanding a quiet network for those walking and cycling. The idea is not without its critics, with opponents suggesting that the measures simply push extra traffic onto busier boundary roads, creating further congestion and pollution. Yet, early evidence from these interventions suggests such concerns lack a substantial foundation (Lambeth Council, 2021), finding that congestion on main roads across the area has remained static pre- and post-intervention, whilst incidents of traffic accidents within the scheme boundaries has dropped substantially.

Although public intervention to implement the 20-minute city is recognised as an important step to promote active travel and liveability, this is not devoid of risks. For example, projects implementing other planning approaches, i.e. New Urbanism, which also advocate for pedestrian accessibility and mix-land use, risk triggering gentrification in certain communities (Markley, 2018), contradicting the underlying spirit of providing improvements for existing residents. Therefore, we argue, along with the characteristics of the built environment and access to services and amenities, equity is a key dimension to be considered while planning for the 20-minute city.

\subsection{Equity and the 20-minute city in Liverpool City Region}

We explore Liverpool City Region as an equity analysis case study for the 20-minute city. Our selection is predicated on two attributes of the city. First, it has limited existing infrastructure to support the 20-minute city, and as such represents what we might call an "average city" in active travel terms and avoids the cherry-picking bias. Second, Liverpool City Region is divided socio-economically, and its inequality is expressed spatially. In the remainder of this section, we briefly reprise the region's historic relationship between inequality and transportation, culminating with the contemporary demand for active travel.

Liverpool City Region's economic growth and decline parallels many post-industrial cities, its aggregate fortune reflecting the waxing and waning of demand for shipping on the River Mersey in North West England. Whilst the City Region's economy is not determined solely by the city of Liverpool, the city is the dominant economic and cultural site in the region.

The region's long history of changing socio-spatial structures is intertwined with changes in transportation and the current spatial distribution of inequalities and neighbourhood services reflects this history. When King John gave the town a royal charter in the 13th century, it enabled the restructuring of land ownership around seven streets and set class-based spatial 
distinctions within the city. By the 18th century, shipping of manufactured goods, raw materials and slaves enabled wealth to be embedded in both the image and built environment of the city as it benefitted from globalising inequality (Munck, 2003). By the mid-nineteenth century, the city had a population density of over 100,000 people per square mile (Dockerill, 2016), denser than almost all the world's current megacities. Through the 19th and 20th centuries new transport infrastructure, from the world's first rail line between Manchester and Liverpool, to tunnels under the Mersey River enabled affluent residents to move from the city centre into topographically and financially separated neighbourhoods (Sykes et al., 2013). During the 20th century, inner city low-income residents were removed to garden estates on the periphery and then further afield to new towns in a form of planned functional separation. Many of these settlements had poor transport connections to the city centre (Power, 2012). By 2005, 38\% of Liverpool's population lived in England's most deprived decile (Rae, 2012). This was not resolved by the urban core's re-population during the 2000 s, as younger professionals and students prioritise proximity to jobs and services moving to the city centre (Dembski et al., 2017), In Liverpool, this reurbanisation, with stagnation in the population in peripheral wards, led to a fragmentation in the distribution of household types, with spatial segregation by age as well as income (Couch and Fowles, 2019).

In 2019, a survey of residents found widespread support for increasing active travel infrastructure and an aspiration to become more active, although there was some variation in cycling appetite between high and lower socio-economic groups (Sustrans, 2020). In 2020, Liverpool City Region Combined Authority announced its Local Cycling and Walking Infrastructure Plan, which identified three phases of active travel intervention. The document includes an analysis of proximity to areas of social deprivation as one of the 12 route prioritisation criteria (LCRCA, 2020a, p.33).

The national impetus to 'build back better' (Johnson, 2020), gave rise to the local microcosm as the city's mayor and City Region's mayor both provided commitments to inclusivity and spatial justice through reimagining travel within the region (Anderson, 2020; LCRCA, 2020b). National funding meant that by the end of 2020, Liverpool City Region was planning for the largest expansion of active travel infrastructure in its history, just as the concept of the 20-minute city was gaining international policy traction. In this context, our study provides evidence of the current state of accessibility to key services for a 20-minute city in Liverpool City Region and uncovers existing inequalities.

\section{Methodology and Data}

The methodology developed in this study generates two outputs: the delineation of areas that approximate 20 minutes neighbourhoods based on accessibility to key services and an equity assessment in LCR.

Firstly, an accessibility score is obtained to capture the extent to which people living in LCR can meet their everyday needs with a 10-minute walk. From such score: 1) spatial clusters of highly served areas have been identified as the best proxy of existing 20 minutes neighbourhoods, and; 2) an equity analysis is undertaken, through OLS and Geographically Weighted Regression models, by investigating global and local relationships between the accessibility score and socio-demographic and environmental variables.

\subsection{Data}

This study relies on three data sources providing: 1) the location of services 2) population-weighted point-based postcode locations and 3) socio-demographic and environmental variables.

The location of services is obtained from Ordnance Survey Point of Interest directory, which contains all public and privately owned businesses, education, and leisure services in Britain, and from the Ordnance Survey Open Greenspace dataset . Taking inspiration from existing literature, several key services for a 20-minute neighbourhood have been selected and mapped to the OS data classification as in Table 1.

Table 1 - List of services which meet most of the basic everyday needs and their mapping with the OS data classification.

\begin{tabular}{|l|l|l|l|}
\hline Service & Specific Service & OS classification & Dataset \\
\hline Food & Specialised Food Shops & Bakeries, Butchers, Confectioners, & OS POI \\
& & Delicatessens, Fishmongers, Tea and & \\
\hline
\end{tabular}




\begin{tabular}{|c|c|c|c|}
\hline & & $\begin{array}{l}\text { Coffee, Merchants, Herbs and Spices, } \\
\text { Grocers, Farm Shops and Pick Your Own }\end{array}$ & \\
\hline Food & General Food Shops & Supermarket & OS POI \\
\hline Transit & Bus & Bus Stops & OS POI \\
\hline Transit & Train & Railway Stations, Junctions and Halts & OS POI \\
\hline Sport & Sport Facilities & Sport Complex & OS POI \\
\hline Green Space & Public Parks & Public Park Access & $\begin{array}{l}\text { OS Open } \\
\text { Greenspace }\end{array}$ \\
\hline Recreational Space & & Recreational & OS POI \\
\hline Education & & First, Primary and Infant Schools & OS POI \\
\hline Health & Doctors & Doctors Surgeries & OS POI \\
\hline Health & Health Products & Chemists and Pharmacies & OS POI \\
\hline Places of Worship & & Places of Worship & OS POI \\
\hline Entertainment & $\begin{array}{l}\text { Places of Cultural and } \\
\text { Entertaining activities }\end{array}$ & $\begin{array}{l}\text { Cinemas, Nightclubs, Social Clubs, } \\
\text { Theatres and Concert Halls }\end{array}$ & OS POI \\
\hline
\end{tabular}

The 12 specific services listed in Table 1 are those used as the destinations of the accessibility score, while the origins are points that approximate where people reside. Specifically, Postcode's code-points are provided by the Ordnance Survey and are the most granular representation of populated areas. After isolating domestic code-points with a unique location, 36095 postcodes remained covering the City Region.

While OS POI and Postcodes are the input data for the accessibility study and the identification of 20-minute neighbourhoods, the equity analysis that follows is based on demographic, socio-economic and environmental variables at Output Area level (Table 2). The initial variable selection aims at addressing critical questions in the domain of transport access and equity. Specifically, how access to services impact demographic (Gaglione et al. 2021), socio-economic and ethnic groups (Foth, Manaugh, \& El-Geneidy, 2013) differently as well as car-dependence and transport-related externalities such as air pollution and traffic accidents (Feitelson, 2002).

Table 2 - Variables Description

\begin{tabular}{|c|c|c|c|c|c|}
\hline Variable & Description & Mean & St. Dev. & Max & Min \\
\hline \multicolumn{6}{|l|}{ Demographic attributes } \\
\hline Population & Estimated Population in 2019 & 306 & 104 & 2643 & 22 \\
\hline Age & Median Age & 41 & 8.6 & 19 & 78 \\
\hline $\begin{array}{l}\text { Black Population (\%) } \\
\text { (2011 Census) }\end{array}$ & $\%$ black population among residents & 0.96 & 2.8 & 48.5 & 0 \\
\hline $\begin{array}{l}\text { White Population (\%) } \\
\text { (2011 Census) }\end{array}$ & $\%$ white population among residents & 95 & 8 & 100 & 14 \\
\hline
\end{tabular}




\begin{tabular}{|c|c|c|c|c|c|}
\hline $\begin{array}{l}\text { Asian Population (\%) } \\
\text { (2011 Census) }\end{array}$ & $\%$ Asian population among residents & 1.9 & 3.6 & 59.2 & 0 \\
\hline $\begin{array}{lr}\text { Multiple } & \text { Ethnicity } \\
\text { Population } & (\%) \quad(2011 \\
\text { Census }) & \end{array}$ & $\%$ multi-ethnicity population among residents & 1.4 & 1.7 & 20.2 & 0 \\
\hline $\begin{array}{lrr}\text { Other } & \text { Ethnicity } \\
\text { Population } & (\%) \quad(2011 \\
\text { Census) } & & \end{array}$ & $\%$ other ethnicity population among residents & 0.6 & 2.1 & 33.1 & 0 \\
\hline Socio-economic attributes & & & & & \\
\hline $\begin{array}{l}\text { Car Ownership } \\
\text { (2011 Census) }\end{array}$ & Number of car or vans owned per 100 inhabitants & 41 & 15.6 & 86.2 & 1.5 \\
\hline $\begin{array}{l}\text { Income Deprivation Score } \\
\text { (IMD 2019) }\end{array}$ & $\begin{array}{l}\text { Measures the proportion of the population } \\
\text { experiencing deprivation relating to low income. A } \\
\text { higher score represents a higher level of deprivation. }\end{array}$ & 0.2 & 0.13 & 0.58 & 0.01 \\
\hline $\begin{array}{l}\text { Education Deprivation } \\
\text { Score (IMD 2019) }\end{array}$ & $\begin{array}{l}\text { Measures the lack of attainment and skills in the } \\
\text { local population. A higher score represents a higher } \\
\text { level of deprivation. }\end{array}$ & 28.8 & 22.2 & 91.8 & 0.2 \\
\hline $\begin{array}{l}\text { Comparative Illness and } \\
\text { Disability Ratio (IMD } \\
\text { 2019) }\end{array}$ & $\begin{array}{l}\text { The comparative illness and disability ratio is an } \\
\text { indicator of work limiting morbidity and disability, } \\
\text { based on those receiving benefits due to inability to } \\
\text { work through ill health. It is an age-sex standardised } \\
\text { measure. A higher score for the indicator represents } \\
\text { a higher level of deprivation. Shrinkage has been } \\
\text { applied to this indicator. }\end{array}$ & 187 & 68.8 & 405.8 & 65.6 \\
\hline $\begin{array}{l}\text { House Prices (based on } \\
\text { ONS yearly values) }\end{array}$ & $\begin{array}{l}\text { Measures } 5 \text { years average house price up } 2015 \text { - } \\
2020 \text {. }\end{array}$ & $£ 139360$ & $£ 70867$ & $£ 748170$ & $£ 7718$ \\
\hline \multicolumn{6}{|l|}{ Environmental attributes } \\
\hline $\begin{array}{l}\text { Air Quality Deprivation } \\
\text { Index (IMD 2019) }\end{array}$ & $\begin{array}{l}\text { The indicator is an estimate of the concentration of } \\
\text { the four pollutants nitrogen dioxide, benzene, } \\
\text { sulphur dioxide and particulates. A higher score for } \\
\text { the indicator represents a higher level of deprivation. }\end{array}$ & 0.95 & 0.18 & 1.4 & 0.47 \\
\hline $\begin{array}{l}\text { Road Traffic Accident } \\
\text { Indicator (IMD 2019) }\end{array}$ & $\begin{array}{l}\text { The indicator is based on reported accidents that } \\
\text { involve death or personal injury to a pedestrian or } \\
\text { cyclist. This indicator is expressed as a rate per }\end{array}$ & 0.88 & 2.28 & 41 & 0.28 \\
\hline
\end{tabular}




\begin{tabular}{|l|l|l|l|l|}
\hline & $\begin{array}{l}1000^{1} . \text { The indicator contains public sector } \\
\text { information licensed under the Open Government } \\
\text { Licence v3.0. }\end{array}$ & & & \\
\hline
\end{tabular}

\subsection{Accessibility to services and the 20-minute neighbourhoods}

Accessibility in land planning has been originally defined by Hansen (1959) as the "potential of opportunities to interaction". Broadly speaking, a measure of accessibility captures the ease with which someone can physically access services, activities, opportunities. Several measures have been adopted to investigate accessibility to destinations; among these, the isochronic or cumulative opportunity measure is widely used (El-Geneidy and Levinson, 2006). Such an approach identifies the number of potential opportunities within a predetermined travel time (or distance). A variation of this approach to fit with the idea of 20minute neighbourhoods is applied to this study. Rather than obtaining isochrones, the routed walking time - obtained through OTP and R (Morgan et al., 2019) -- to the five nearest (based on Euclidean distance) destinations from each postcode are calculated for each category of service; the shortest travel time to each distinct category of service is then selected and averaged at the Output Area level. To obtain a 20-minute neighbourhood accessibility score a binary value 1-0 is assigned every time the average walking time to a category of service from each Output Area is lower or equal to 10 minutes. The final score is the count of all categories that meet such a constraint. Ideally, a 20-minute neighbourhood would have at least one facility, reachable in a 10-minute walk, for each category of service, therefore scoring 12 , which is the total number of service types considered in this study (see Table 1). To capture groups of OAs that have the highest number of distinct accessible categories of services, and therefore better approximate a 20-minute neighbourhood, global and local spatial clustering statistics of the number of accessible services in the Liverpool City Region are employed.

Firstly, the global Moran Index is tested. It is a widely employed metric to evaluate the level of spatial clustering, or spatial autocorrelation, present in the data (Seya, 2020). A spatial autocorrelation index measures the spatial regularity of a geographically distributed phenomenon: a positive value means that the attributes of neighbouring data points are systematically more similar to each other than to those at a farther distance, while negative values indicate dissimilarity; an index score that equals to or close to 0 suggests that the variable of interest distributes across space randomly. The resulting index value must be interpreted against the null hypothesis significance testing so that the $\mathrm{p}$ value must be lower than 0.05 .

Secondly, the Local Moran Index (Seya, 2020) - or Local Indicator of Spatial Autocorrelation (LISA) - is computed to identify hot spots of OAs with high accessibility which can be ascribed as existing 20-minute neighbourhoods in the study area. While the global Moran Index tests whether the data is not randomly distributed across space or not, a LISA provides for each observation a measure of the extent to which significant clustering of similar values is present in proximity to the observation. The resulting local index is defined as the similarity between the deviation of its value from the mean value and the deviation from the mean of the observed neighbouring values. As for the global index positive or negative values along with a significatively low $p$ value indicates a positive or negative spatial autocorrelation, while values near zero means there is no relationship with the surrounding values.

For both global and local spatial statistics, it is necessary to define a priori the form of the spatial dependence structure (Seya, 2020). In this case, given the values are at Output Area level, whose polygons do not have regular shapes, a contingencybased structure is chosen (rather than distance-based). Specifically, a Queen neighbouring structure with binary weights is adopted.

From the local spatial statistics, it is eventually possible to identify spatial clusters of Output Areas with high accessibility to a wider number of services, which we propose to consider as a good approximation of a 20-minute neighbourhood.

\subsection{Equity Analysis}

The relationships between the level of service accessibility with the socio-demographic and environmental variables shown in Table 2 is explored through OLS and Geographically Weighted Regression (GWR) models to uncover existing inequalities across the region. A large body of studies shows how often service accessibility disparities exist among different

\footnotetext{
${ }^{1}$ Note that to take into account the number of people in the local area during the day this ratio uses as denominator the non-resident workplace population.
} 
demographic, ethnic or socioeconomic groups (Yin et al. 2018), highlighting the need to include access to services in transportation planning, rather than only focussing on mobility (Proffitt et al. 2019). Furthermore, combining OLS and GWR is a widely used approach to explore equity in the spatial distribution of services (Park and Gouldmann, 2020).

While the dependent variable of these models is the number of different services types accessible at each OA, the direction of such dependency can be questioned (i.e., the number of services and air quality). It is, therefore, important to note that the objective is to investigate the existing relationships between accessibility to a variety of services and socioeconomic and environmental variables in light of an equity analysis, and the independent variables do not have to be considered as predictors.

The initial variable selection followed the rationale of obtaining relevant knowledge around accessibility and equality by including social, demographic, economic and environmental variables which to various regards can be linked to structural inequalities, such as ethnicity or income, or belong to the transportation domain, such as car ownership or air quality.

However, a further selection is carried out to achieve the most accurate model output. The performances of the first set of Ordinary Least Squares (OLS) Regression models are assessed evaluating both the goodness of fit and the Akaike information criterion (AIC) (Heinze et al., 2018) and analysing the variance inflation factor (VIF) to avoid collinearity generally, a VIF above five suggests multicollinearity (Harris and Jarvis, 2014).

The resulting set of variables are then used in the GWR model to obtain local statistics. Although multicollinearity has been removed in the OLS it can be present among the local statistics. Therefore, a further set of diagnostics is applied by controlling the absence of correlation among local coefficients and the randomness in the distribution of residuals through a Moran test to evaluate the model performance.

While OLS models provide information on global relationships between a dependent and several independent variables, GWR assumes that such relationships may differ from location to location (Fotheringham et al., 2002). Therefore, through a GWR it is possible to obtain a set of local regression to location (Fotheringham et al., 2002). Based on Tobler's (1970) First Law of Geography, all observed data points in GWR are weighted by their spatial proximity to the regression point, giving more relevance to closer data points (Fotheringham et al., 2002). Consequently, it is important to define the more appropriate bandwidth and kernel (density) function, which determine the spatial dependency structure to rely on in the model.

The bandwidth selection process with an adaptive approach returns a value for the optimal proportion of neighbouring observations, and it is more appropriate than a fixed-bandwidth when there are polygons of varied sizes - the size of the bandwidth increases when the observed data points are widely spaced and decrease when they are closer. In the basic GWR, during model calibration, bandwidths are tested to minimize the cross validation (CV) scores and produce the lowest root mean square error (Fotheringham et al., 2003), while in multiscale GWR a back-fitting algorithm is used (Fotheringam et al. 2017). A bi-square kernel function is used to capture variable variations across a wider data sample. The significance of each local estimate is determined by a classic t-test, therefore a correction factor to multiple hypothesis tests is needed (da Silva and Fotheringham, 2016). This is applied following Yu et al. (2020) approach and carrying out the GWR analysis through the mgwr Python PySAL library (Oshan et al. 2019).

\section{Results}

\subsection{0-minute neighbourhoods in Liverpool City Region}

An exploration of accessibility to services in light of the idea of identifying 20-minute neighbourhoods in Liverpool City Region (LCR) is carried out.

Figure 1 shows which services people living in LCR can access more frequently within a 10-minute walk. From all Output Areas in LCR people can access a bus stop in less than a 10-minute walk; while this is indicative of the presence of widespread bus infrastructure, it is important to note that it does not give us information on the bus routes network performance. For more than a third of the LCR population, it is possible to reach at least one sports complex and place of worship. Primary schools, pharmacies and public parks are up to a 10-minute walking distance for about $60 \%$ to $65 \%$ of the population while around half of the population can walk to the closest GP, recreation space and a specialised food shop in ten 
minutes. The less frequent amenities are those related to entertainment, supermarket and train stations with $37 \%, 29 \%$ and only $14 \%$ of the population respectively able to access them in a 10 -minute walk.

It is evident that services are not evenly distributed across space and some areas tend to have higher accessibility than others. Along with an analysis of individual categories of services, we are interested in what areas have higher accessibility to a combination of such services and therefore better approximate a 20-minute neighbourhood. For each Output Area the number of categories of service is counted with a maximum of 12 distinct accessible categories. Only those living in $1 \%$ of the Output Areas can reach services from all 12 categories in a 10-minute walk, while the average number of service types accessible is seven out of 12 . Figure $2 \mathrm{~B}$ shows how this accessibility score, counting the number of distinct categories of services reachable in a 10-minute walk, is distributed across Liverpool City Region.

Figure 1 - Population (\%) which can access at least one service within 10-minute walk by category of service.

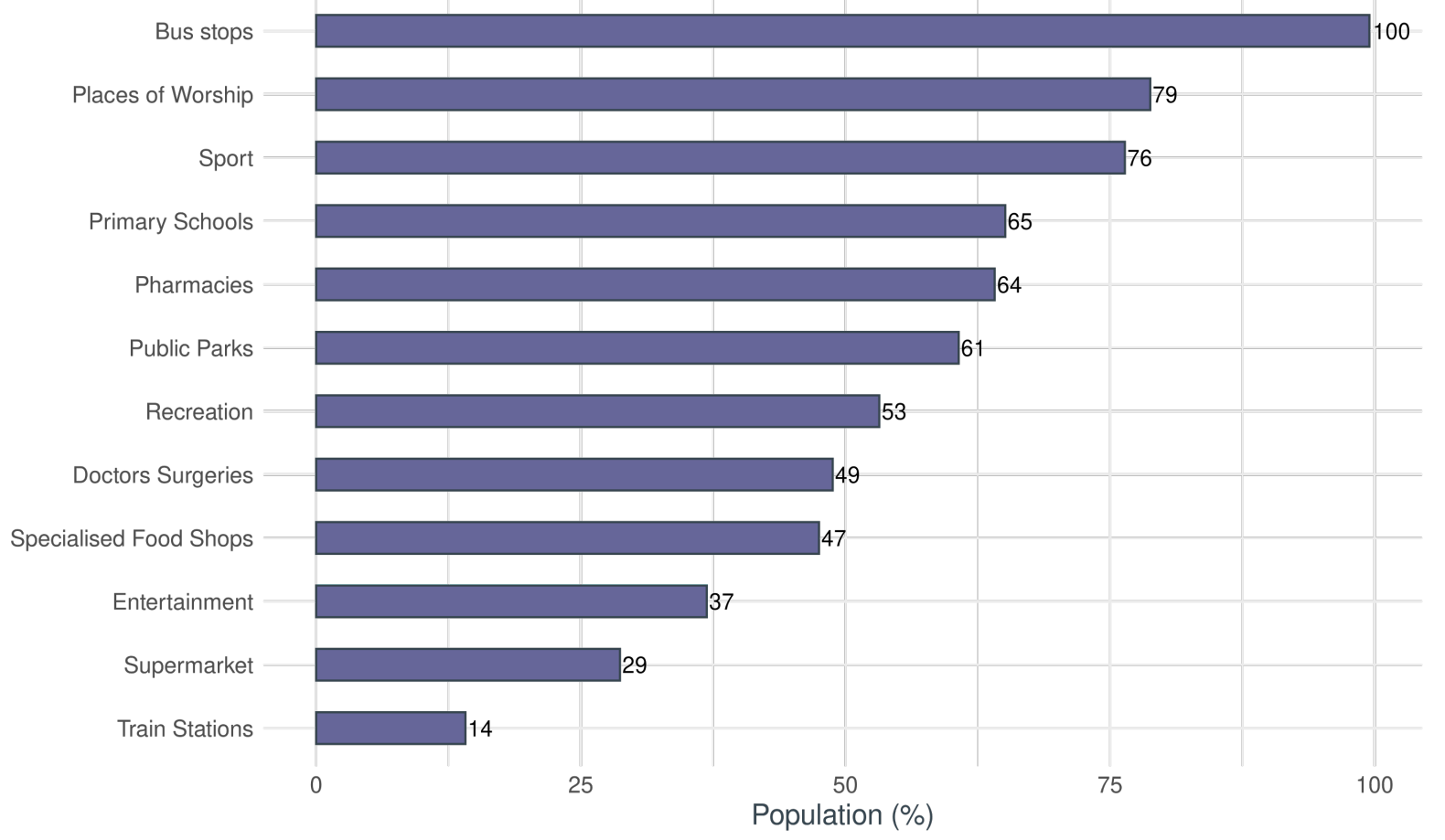

We also investigate the extent to which the types of services accessible are spatially clustered using the Moran Index. It gives a value of 0.6 with a $\mathrm{p}$-value $<=.001$, confirming that there is a high level of spatial clustering among the observations. To identify which areas show a high level of accessibility and tend to be more spatially clustered, a Local Indicator of Spatial Correlation is calculated. Local Moran Index measures are associated with each Output Area and, combining positive coefficients with the level of significance and the standardised accessibility value, it is possible to delineate areas surrounded by others that display similar accessibility features. Figure 2A shows combinations of high or low accessibility accompanied by a positive and significant spatial autocorrelation. The areas in yellow can be considered as those that better approximate the idea of a 20-minute neighbourhood as they have both a high level of accessibility to a wider spectrum of services and positive spatial autocorrelation, therefore have similar neighbours. The map also shows that 20-minute neighbourhoods are mostly located in the urban cores of each local authority and are surrounded by strips where the number of accessible services observed is distributed randomly (non-significant spatial autocorrelation); while at the outskirts and more rural areas we find most of the low access neighbourhoods. People living in high access neighbourhoods can reach ten different services on average, while the global average is seven, and those living in low access neighbourhoods only three.

Currently, people living in the 20 neighbourhoods correspond to a minimum of only $2.4 \%$ of the population in Knowsley up to a maximum of $24 \%$ of the population in Liverpool (see Figure 3 ).

\subsection{OLS and GWR}


The second objective of this study, following the identification of 20-minute neighbourhoods, is to carry out an equity analysis by investigating the relationships between accessibility levels and socio-demographic variables, as well as considering whether higher accessibility can benefit the environment. Table 2 shows the variables that have been analysed in two types of models: OLS regression and GWR.

Several OLS models have been tested to select the best set of variables. Specifically, Table 3 shows all the OLS results with the corresponding VIF values. Model 3 includes both demographic, social, and environmental variables and it is the best performing model having all significant coefficients, better R-squared, lower AIC, and no sign of collinearity (VIF<5). Results from Model 3 show that both population and ethnicity have almost no relationship with the level of accessibility, suggesting that the distribution of services do not disproportionately advantage or disadvantage any specific cultural group.

Figure $2-A$ ) Standardized level of service access in combination with the Local Indicator of Spatial Autocorrelation (significance pvalue $<0.05)$. Yellow areas indicate high accessibility to a wide variety of services and being surrounded by other similar areas. These better approximate 20-minute neighbourhoods. Dark blue areas have low accessibility and are surrounded by areas with low accessibility. B) Count of the distinct services types that are accessible in 10 minute walk.

A

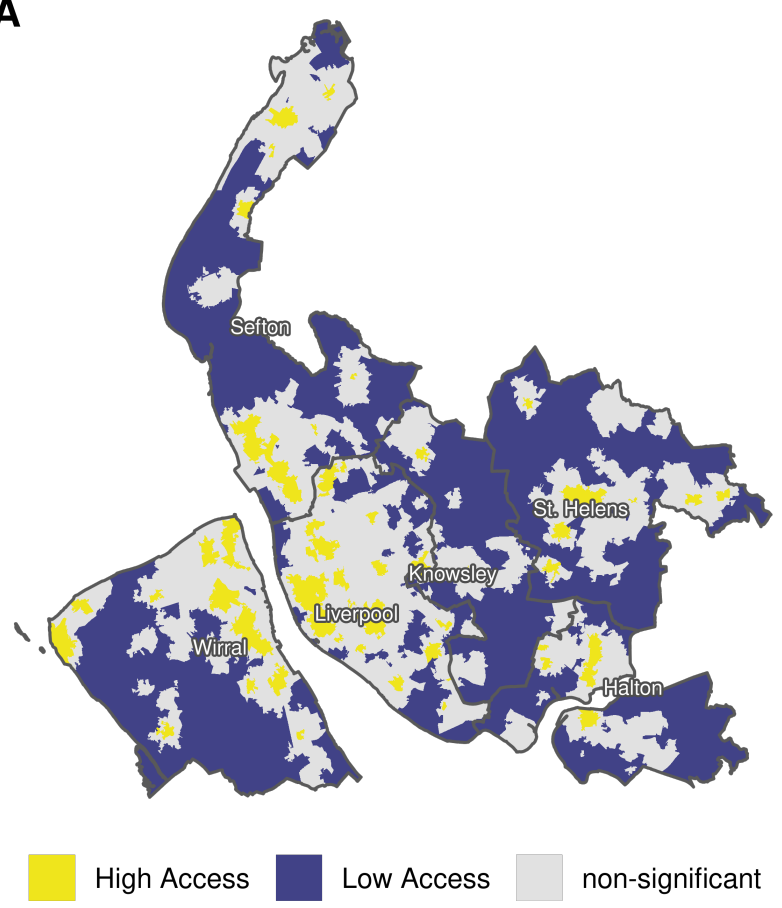

B

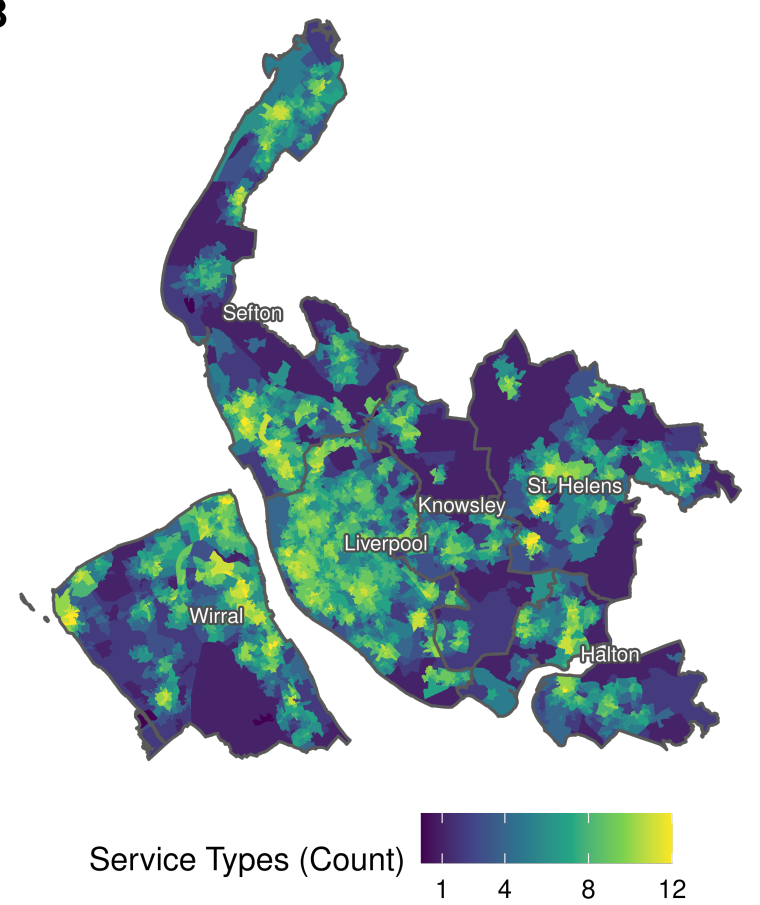

Likewise, environmental variables do not show any strong relationship with the accessibility score at a global level. On the contrary, there is a rather strong negative relation between the services accessible in a short walk and two socio-economic variables: car ownership and the education deprivation score.

Figure 3 - Population (\%) living in 20-minute neighbourhoods by Local Authority 


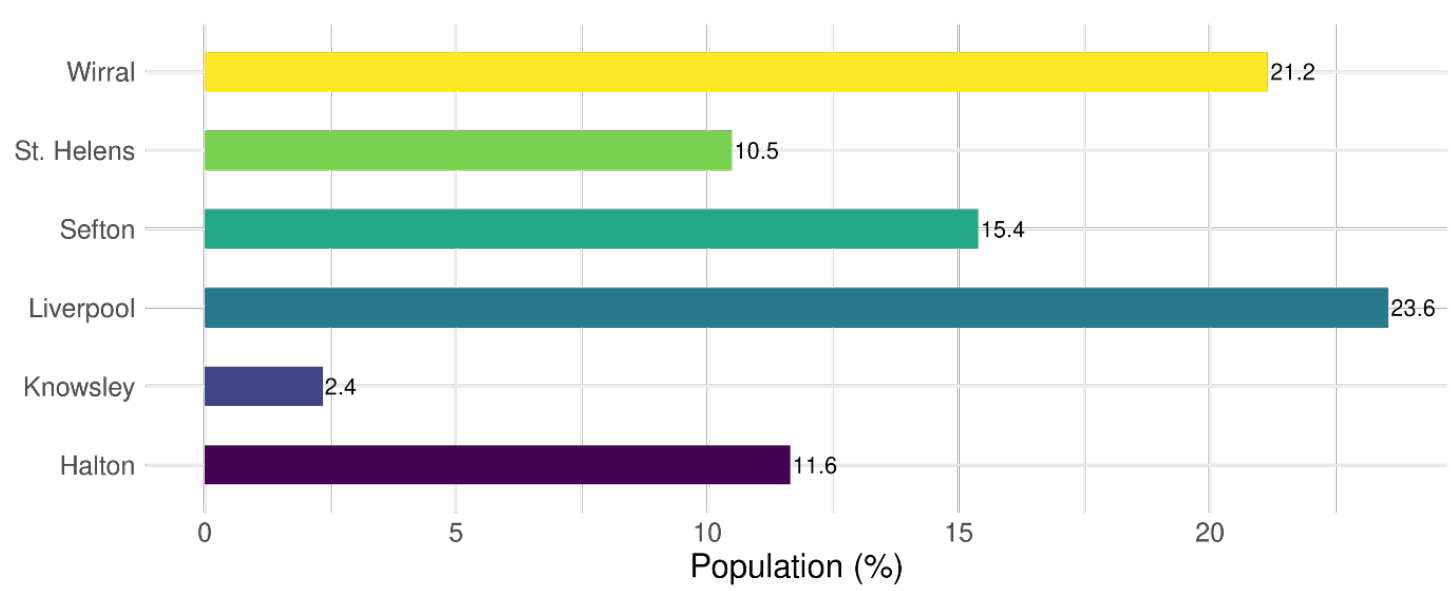

Table 3 Summary of the OLS models - Dependent Variable: Accessible Service Score (ORQ)

\begin{tabular}{|c|c|c|c|c|c|c|c|c|c|}
\hline \multirow[b]{2}{*}{ Variables } & \multicolumn{3}{|c|}{ Model 1} & \multicolumn{3}{|c|}{ Model 2} & \multicolumn{3}{|c|}{ Model 3} \\
\hline & $\beta$ & St. Err. & VIF & $\beta$ & St. Err. & VIF & $\beta$ & St. Err. & VIF \\
\hline \multicolumn{10}{|l|}{ Demographic } \\
\hline Population (ORQ) & $-0.09 * * *$ & .014 & 1.09 & $-0.02 *$ & .01 & 1.14 & $-0.04 * * *$ & 01 & 1.03 \\
\hline Median Age (ORQ) & $-0.18 * * *$ & .015 & 1.31 & -0.006 & .01 & 1.83 & & & \\
\hline Black (\%) (sqr) & 0.01 & .019 & 2.07 & $-0.08 * * *$ & .01 & 1.89 & $-0.06 * * *$ & .01 & 1.86 \\
\hline White (\%) (ORQ) & -0.002 & .04 & 8.75 & & & & & & \\
\hline Asian (\%) (arcsinh) & -0.003 & .026 & 3.85 & 0.02 & .01 & 1.49 & & & \\
\hline mltEthn (\%) (arcsinh) & $0.07 * *$ & .023 & 2.98 & $0.04 * *$ & .01 & 1.52 & $0.04 * *$ & .01 & 1.45 \\
\hline otherEthn (\%) (sqr) & $0.07 * * *$ & .017 & 1.69 & $0.03 *$ & .01 & 1.68 & $0.05 * * *$ & .01 & 1.59 \\
\hline \multicolumn{10}{|l|}{ Socio-Economic } \\
\hline Car Own (ORQ) & & & & $-0.54 * * *$ & .02 & 3.52 & $-0.42 * * *$ & .02 & 3.26 \\
\hline IMD Edu (ORQ) & & & & $-0.42 * * *$ & .03 & 7.04 & $-0.3 * * *$ & .02 & 4.2 \\
\hline IMD Income (ORQ) & & & & $-0.18 * * *$ & .03 & 9.27 & & & \\
\hline IMD Disability (ORQ) & & & & -0.03 & .03 & 9.7 & & & \\
\hline House Prices (ORQ) & & & & $-0.13 * * *$ & .02 & 4.1 & $-0.1 * * *$ & .02 & 4.1 \\
\hline \multicolumn{10}{|l|}{ Environmental } \\
\hline IMD AirQ (ORQ) & & & & & & & $0.09 * * *$ & .01 & 1.73 \\
\hline Traffic Injuries (ORQ) & & & & & & & $-0.04 * * *$ & .01 & 1.25 \\
\hline Adjusted R-squared & & 0.06 & & & 0.21 & & & 0.21 & \\
\hline$A I C$ & & 14098.64 & & & 13243 & & & 13237 & \\
\hline Residual - Moran & & $0.62 * * *$ & & & $0.56 * * *$ & & & $0.56^{* * *}$ & \\
\hline
\end{tabular}


Index

Normalization method under brackets.

$* p<.05 * * p<.01 * * * p<.001$.

We note that while education deprivation and car ownership can be associated with income and have a strong negative correlation (-0.75), these two effects move in the same direction, suggesting that there could be low income areas where people experience low access to both services and cars. Model 3 also shows a relatively poor fit and exhibits significant levels of residual spatial autocorrelation. As a consequence, the results presented above need to be interpreted with caution taking into account that they provide a biased description of the observed phenomenon, which does not account for its underlying spatial patterns.

To better investigate how these relationships vary across space we undertake a GWR analysis. Overall, the OLS regression allows us to identify the best set of variables to model - those showing a lower level of collinearity -- and provides the baseline against which any form of GWR can be then compared with (Comber et al., 2020 ).

Similarly to the OLS model, the variables which overall show a stronger relationship with the accessibility of the services are the socio economic and environmental variables. The sign of these relationships changes from positive to negative over space, highlighting the non-stationarity of these relationships and suggesting that inequitable conditions of access are to varying degrees related with different factors. Maps of both GWR and multiscale GWR coefficients with a significance level at $95 \%$, along with the standardised distribution of all variables are available in the Appendix (see A1). The multiscale GWR model performs significantly better than GWR, with the higher Adj.R-squared and lower AICc, as well as not showing a sign of spatial autocorrelation among the residuals. Furthermore, the diagnostics on local multicollinearity are not problematic as all below the rule of thumb of 30 (Oshan et al., 2019).

Table 4 Summary of the GWR models-Dependent Variable: Standardized Accessible Services Score (ORQ). Bandwidth is accompanied by their respective Confidence Interval (CI).

\begin{tabular}{|c|c|c|c|c|c|c|c|c|c|c|c|}
\hline \multicolumn{7}{|c|}{ Basic GWR, bw 102 (CI 101-104) } & \multicolumn{4}{|c|}{ Multi-scale GWR } & \multirow[b]{2}{*}{$\mathrm{Bw}(\mathrm{CI})$} \\
\hline Variable & Mean & STD & Min & Median & Max & Mean & STD & Min & Median & Max & \\
\hline \multicolumn{12}{|l|}{ Demographic } \\
\hline Population & -0.046 & 0.128 & -0.491 & -0.036 & 0.380 & -0.033 & 0.058 & -0.178 & -0.034 & 0.111 & $\begin{array}{l}307 \\
(285-311)\end{array}$ \\
\hline Black & -0.026 & 0.214 & -0.872 & -0.011 & 0.9 & 0.044 & 0.085 & -0.137 & 0.034 & 0.39 & $\begin{array}{l}449 \\
(435-461)\end{array}$ \\
\hline mltEthn & -0.004 & 0.138 & -0.652 & -0.003 & 0.436 & -0.009 & 0.03 & -0.053 & -0.014 & 0.077 & $\begin{array}{l}1337 \\
(1203-1486)\end{array}$ \\
\hline otherEthn & 0.014 & 0.227 & -1.033 & 0.01 & 0.858 & 0.077 & 0.131 & -0.22 & 0.063 & 0.870 & $\begin{array}{l}165 \\
(151-177)\end{array}$ \\
\hline \multicolumn{12}{|l|}{ Socio-Economic } \\
\hline Car Own & -0.305 & 0.291 & -1.231 & -0.297 & 0.618 & -0.18 & 0.16 & -0.769 & -0.161 & 0.367 & $\begin{array}{l}95 \\
(95-95)\end{array}$ \\
\hline IMDeduS & -0.152 & 0.545 & -2.013 & -0.183 & 2.578 & -0.031 & 0.216 & -0.54 & -0.038 & 0.793 & $\begin{array}{l}143 \\
(136-143)\end{array}$ \\
\hline $\begin{array}{l}\text { House Price } \\
(5 \text { yrs avg) }\end{array}$ & -0.153 & 0.587 & -2.847 & -0.169 & 2.804 & -0.072 & 0.11 & -0.258 & -0.112 & 0.12 & $\begin{array}{l}552 \\
(461-569)\end{array}$ \\
\hline \multicolumn{12}{|l|}{ Environmental } \\
\hline IMD air & 0.282 & 0.664 & -2.414 & 0.280 & 2.713 & 0.094 & 0.307 & -0.757 & 0.048 & 1.89 & $\begin{array}{l}63 \\
(59-69)\end{array}$ \\
\hline Traffic Injuries & 0.062 & 0.358 & -1.093 & 0.046 & 3.209 & 0.543 & 0.936 & -1.512 & 0.269 & 6.306 & $\begin{array}{l}51 \\
(49-53)\end{array}$ \\
\hline
\end{tabular}




\begin{tabular}{ll|l}
\hline Adj.R-squared & 0.568 & 0.79 \\
AICc & 11692.444 & 9043 \\
Residual MI & $0.28^{* * *}$ & 0.012 \\
\hline
\end{tabular}

The relationship between services access and car ownership in the multiscale GWR does not confirm everywhere the global estimate. On the one hand, almost all of the significant results are negative (Figure 4A) - with the only exception of an area in Liverpool South (Figure 4B). On the other hand, it is apparent that the significant coefficients spatially distribute in $\mathrm{rural} /$ peripheral areas covering $85 \%$ of the data points classified as rural and only $11 \%$ of urban major conurbation (Figure 4C). Although in urban major conurbations access to services is generally higher than in rural areas, the absence of a significant negative relation between services and car ownerships prevents us to rule out the possibility for some to experience simultaneously low access to services and low car ownership or high access and high car ownership.

Education deprivation has a global negative relationship with access but also shows significant local variations with either positive or negative coefficients demonstrating an unbalanced distribution of basic services across different levels of education (Figure 5A). However, it is noticeable that most of the negative coefficients correspond with areas of a generally lower level of education while positive coefficients are more likely in areas where more highly educated people live (Figure 5B). Given that the level of education is often related with income, areas with lower education and a negative relationship with access to services should be of special concern for policymakers as people living in these areas have fewer resources to satisfy their daily needs.

Figure 4-A) Map of multiscale GWR coefficients for car ownership (dependent variable: access to services score). Grey areas are nonsignificant at 95\% level; B) A small cluster of positive coefficients is located around Sefton park towards Mossley Hill; this is a wealthy area of Liverpool, where access to a wider types of services is accompanied by higher car ownership; C) \% of significant and nonsignificant observation among rural and urban areas. This plot shows that the negative relationship between services access and car ownership characterises mostly rural areas and towns. Classes are based on the ONS 2011 Rural-Urban Classification.

A

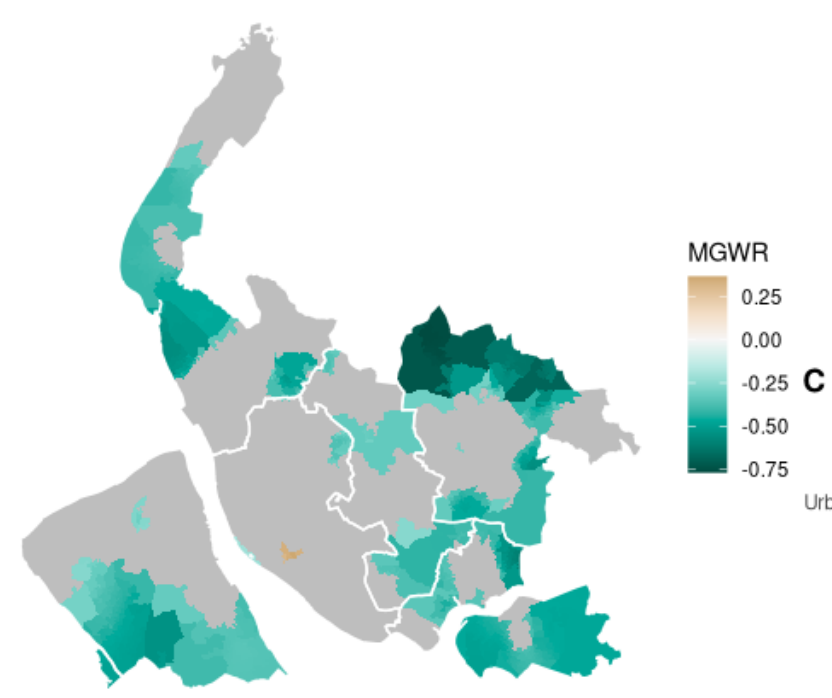

B

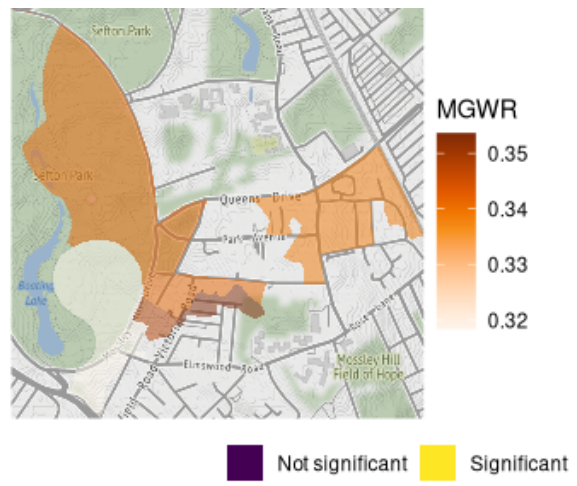

Urban major conurbation

Urban city and town

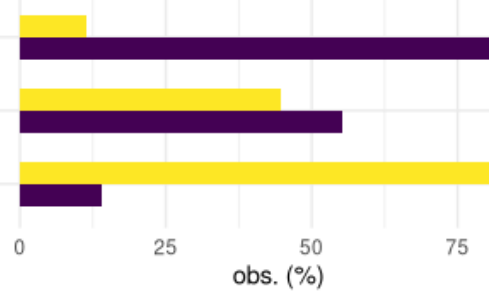

Similarly to the OLS regression in the multiscale GWR house prices do not show a strong relationship with access to services; however, it is interesting to see that the significant coefficients are mostly present in areas with house prices higher than the Liverpool City Region average (Figure 6A). This suggests that in wealthier areas the presence of services does not seem to be an added value, on the contrary, the lower the services the higher the prices. This could be due to more expensive houses being located in less dense (and therefore less served by walk) areas and/or to a disvalue associated with a possible increase of noise when more services are present. In the context of more disadvantaged areas, with relatively less expensive houses, the presence of services does not seem to significantly relate with house prices. 
Finally, mapping the level of air quality deprivation in Liverpool City Region we note that most of the areas approximating 20-minute neighbourhoods are located in relatively more polluted areas (Figure 7A). While we found only a weak and positive relation between air quality deprivation and walkable access to services in the OLS, this becomes stronger while modelled in the multiscale GWR (Figure 7B). However, most of the significant values are in areas outside Liverpool where people benefit from a relatively better air quality.

\section{Discussion}

The 20-minute city has been presented as an unambiguous normative good for cities. Transport and urban planners have been tasked with retrofitting the 20-minute city to existing urban structures with the hope of meeting people's everyday needs locally. Whilst the 20-minute city does offer the potential to support a wide range of environmental, social, and economic public policy targets, its merit for individual citizens is predicated upon how and where it is implemented. Furthermore, its implementation may re-distribute the quality of environmental attributes. Prior to this research, there had been little exploration of how social equity and environmental effects correlate spatially with existing 20-minute city neighbourhoods. From our spatial equity analysis of Liverpool City Region, we identify socio-economic inequality of access to the variety of services required to satisfy people's everyday needs and raise environmental concerns.

Figure 5-A) Multiscale GWR coefficients for the Education Deprivation Score (dependent variable: access to services score). Grey areas are non-significant at 95\% level; B) Distributions of significant positive and negative coefficients across different level of education. This shows that negative values correspond to areas with a higher than average education deprivation, while positive values correspond to areas with a lower level of deprivation.

A

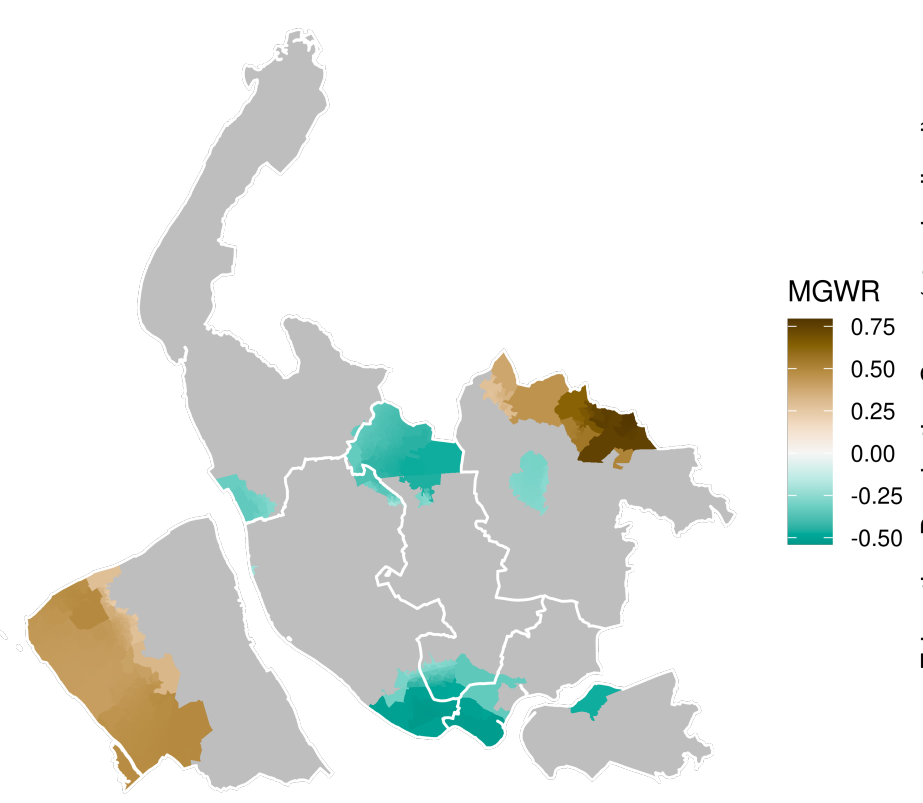

B

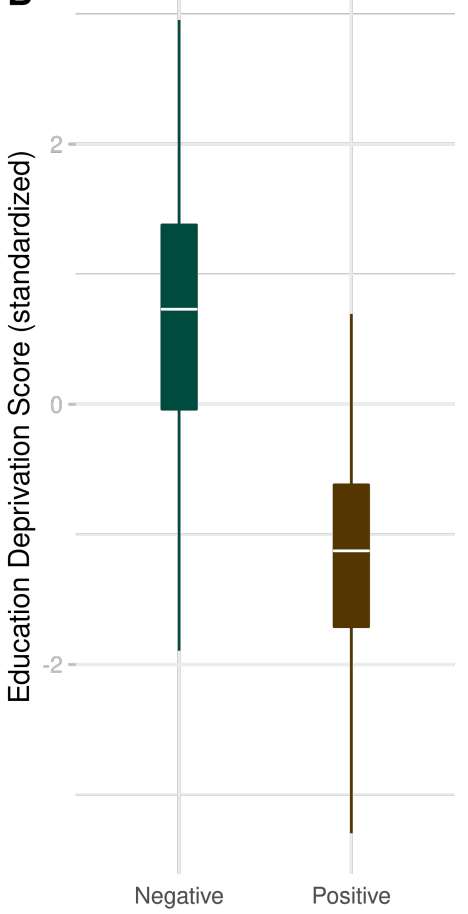

Figure 6-MGWR coefficients for the 5-year house prices average (dependent variable: access to services score, grey areas are nonsignificant at 95\% level) in A) areas with higher than average house prices, B) areas with lower than average house prices. These maps show that most of the significant values are spatially distributed in areas with higher than average house prices $(A)$. 
A

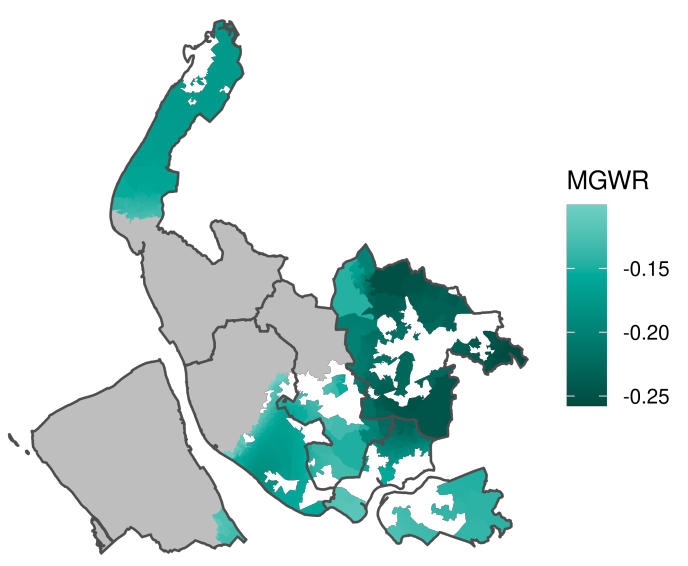

B

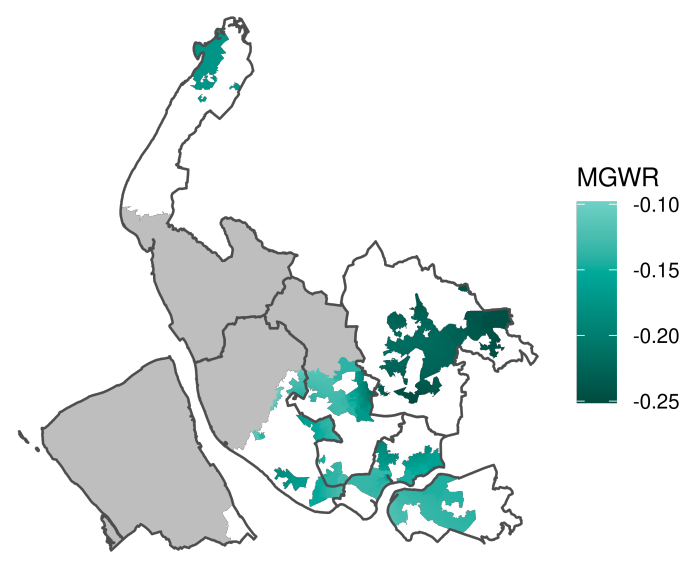

Figure 7 - A) Standardised distribution of air quality deprivation; black boundaries are the areas that approximate 20-minute neighbourhoods determined as described in Section 3.2; B) Multiscale GWR coefficients for air quality deprivation (dependent variable: access to services score, grey areas are non significant at 95\% level) .

A

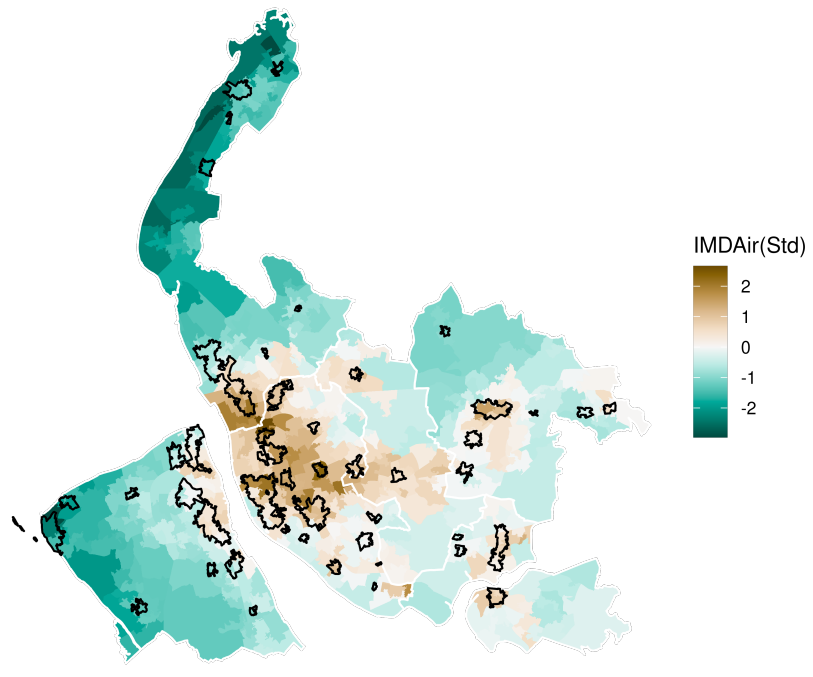

B

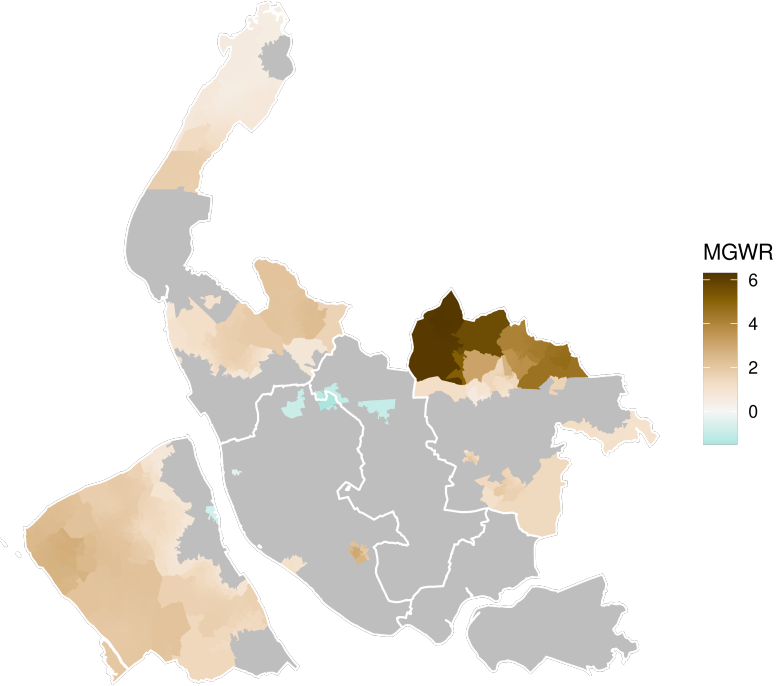

Overall, only a small proportion of Liverpool City Region's population lives in high access areas, which could approximate 20-minute neighbourhoods. Further information on the socio-economic attributes and exposure to pollution across areas with different levels of service access can support policy-making aimed at a more equitable service distribution.

Whilst the 20-minute city is focussed on active travel, the relationship with existing car use is significant, as cities seek to move away from the functional separation that was planned in the 20th century, which continued to exacerbate destination accessibility for many (Ewing and Cervero, 2010). This study explores the relationship between car ownership and accessibility and shows it weakening within some urban areas. People living in such areas with low car ownership and low accessibility indicates structural inequalities that policymakers should aim to address. Low access to services in more deprived areas can also bring what Mattioli (2017) called 'forced car ownership'. Not only do people living in less walkable neighbourhoods have this inconvenience, they also must absorb higher transport costs. A similar problem is highlighted in areas with a strong negative relationship between education deprivation and access - as emerged around Bootle, Speke and in parts of Halton and Knowsley - which often corresponded to lower incomes. At the same time in some highly served areas 
such as Mossley Hill, we also see high car ownership levels, which could be related to higher financial capacity and the "car culture' of contemporary societies (Mattioli et al., 2020) than on the need for local transport.

A reduction in air pollution and car traffic is one of the positive outcomes of an increase in active travel (Brand et al., 2021). Although we would expect more active travel in highly served areas and therefore also lower levels of pollution, this analysis shows that many of the high access neighbourhoods - particularly those in Liverpool - tend to also have higher levels of pollution. This is due to a variety of reasons. First, we use air quality as the indicator, but this comprises both locally produced air pollution (e.g., car exhaust fumes) and wider pollution sources (e.g., up-wind factories). Second, it is important to note that accessibility is different from mobility: the latter expresses actual movements of people, the former is about the potential of an area to enable mobility to destinations (Papa, 2020). Pollution may be caused by people choosing to travel further to access services that they prefer (e.g., specialist food stores) rather than their more mundane needs (e.g. local grocery store). While distance to key services is an important driver of active travel, to make an area walkable other urban design elements also need to be considered (Forsyth, 2015). Furthermore, not all services are of the same quality and people might prefer to travel further for higher quality services. The measure of access analysed in this study does not consider variations in quality nor the built environment quality. Therefore, rather than being a proxy for active travel, it is a good indication of where interventions - both related to physical changes of the urban fabric or policies such as Low Traffic Zones -- could be more effective in increasing active travel since there is already a wider variety of services accessible by walking.

As commuting is not addressed in the present study, further analysis on work-places will be undertaken, particularly considering an increase in work-at-home due to the COVID-19 pandemic. However, as Budnitz et al. (2020) show commuting is not the main reason for travel, so its impact should not be overestimated and even in a situation of high remote working, we can still see a high level of pollution because of non-work-related trips.

\section{Conclusion}

The COVID-19 pandemic has significantly increased policy attention on active travel, with the 20-minute city emerging as an urban transportation goal internationally. The resurgence of the "local" neighbourhood within cities and the modal shift of some urban transit patterns have supported the idea of residents' daily and weekly needs being met in close time-proximity to their dwellings, through enhanced active travel.

The ability of urban neighbourhoods to meet the requirements of the 20 -minute city is often unequally distributed across cities, predicated upon both existing urban morphology and extant patterns of spatial inequalities. Yet, the 20-minute city is often presented as an equitable force for enhancing all citizens' well-being, ignoring, or at best hopefully re-imagining, the impact of planning for new services and active travel support on existing spatial inequalities. Thus, we have argued for the need for methods to identify where and how neighbourhoods of the 20-minute city could be created that mitigate rather than exacerbate existing spatial inequalities. Specifically, this study is a first step towards the definition of a toolkit to support planning for the 20-minute city while accounting for equity. Further analyses are also required to assess cycling access to services in Liverpool City Region, as well as to elicit more specific accessibility needs - an interesting approach is presented in Di Ciommo (2018).

Overall, there is an inherent transport and urban planning policy tension in our analysis. On the one hand, our novel method of identifying areas that approximate 20-minute neighbourhoods could enable policymakers to cherry-pick areas for planning. Highly served areas are closer to the idea of the 20-minute city neighbourhood and indicate where it would be easier to create a liveable and healthy neighbourhood, that also incentivise active travel, as most services are easily accessible. On the other hand, areas that have fewer services, those that are further from the 20-minute city ideal, are often already disadvantaged and highly car-dependent. Hence, in their desire to create the 20-minute city, policymakers must choose to prioritize easier to implement areas or to tackle existing inequality, even if they require more substantial interventions. In our work we show that in the context of Liverpool City Region most of the variations in access to services are related to socio-economic factors; 20minute city neighbourhoods are not neutrally distributed. Whilst air quality is worse in some highly serviced neighbourhoods, there are options for planning to limit access to car traffic and support lower-polluting transport options. Furthermore, the overall improvements in air quality arising from a modal shift to active travel offer enhancements to overall air quality.

The 20-minute city has the potential to provide multiple benefits for residents. But, to prevent its application from impacting negatively on those most disadvantaged, we need to clearly understand the relationship with existing inequalities and care 
needs to be taken to implement the 20-minute city equitably. More disadvantaged areas will need additional support as part of an equity approach to planning the city region if the 20 -minute city is to be inclusive, fair, and socially just.

\section{Acknowledgment}

This publication was supported by the Economic and Social Research Council, project reference ES/L011840/1, and carried out in collaboration with Liverpool City Region within the Parnership Recovery and Resilience scheme at University of Liverpool.

\section{References}

Aldred, R., Croft, J. and Goodman, A., (2019) Impacts of an active travel intervention with a cycling focus in a suburban context: One-year findings from an evaluation of London's in-progress mini-Hollands programme. Transportation research part A: policy and practice, 123, pp.147-169.

Bills, T.S. \& Walker, J.L. (2017) Looking beyond the mean for equity analysis: Examining distributional impacts of transportation improvements. Transport Policy, 54, pp.61-69.

Brand, C., Dons, E., Anaya-Boig, E., Avila-Palencia, I., Clark, A., de Nazelle, A., Gascon, M., Gaupp-Berghausen, M., Gerike, R., Götschi, T. and Iacorossi, F. (2021) The climate change mitigation effects of daily active travel in cities. Transportation Research Part D: Transport and Environment, 93, p.102764.

Budnitz, H., Tranos, E., \& Chapman, L. (2020) Telecommuting and other trips: an English case study. Journal of Transport Geography, 85, 102713.

C40 Cities Climate Leadership Group, C40 Knowledge Hub (2021) How to build back better with a 15 minute city?, Accessed at: https://www.c40knowledgehub.org/s/article/How-to-build-back-better-with-a-15-minute-city?

Capasso Da Silva, D., King, D.A. \& Lemar, S. (2020) Accessibility in practice: 20-minute city as a sustainability planning goal. Sustainability, 12(1), p.129.

Carr, L. J., Dunsiger, S. I., \& Marcus, B. H. (2010) Walk score ${ }^{\mathrm{TM}}$ as a global estimate of neighborhood walkability. American journal of preventive medicine, 39(5), 460-463.

Comber, A., Brunsdon, C., Charlton, M., Dong, G., Harris, R., Lu, B. \& Harris, P. (2020) The GWR route map: a guide to the informed application of Geographically Weighted Regression. arXiv preprint arXiv:2004.06070.

Couch, C. \& Fowles, S. (2019) Metropolitan Planning and the Phenomenon of Reurbanisation: The Example of Liverpool, Planning Practice \& Research, 34 (2), pp.184-205

Deboosere, R., El-Geneidy, A. M., \& Levinson, D. (2018) Accessibility-oriented development. Journal of Transport Geography, 70, 11-20.

Dembski, S., Schulze-Baing, A. 7 Sykes, O. (2017) What about the Urban Periphery? The Effects of the Urban Renaissance in the Mersey Belt, Comparative Population Studies, 42, pp.219-244

De Silva, A. R., \& Fotheringham, A. S. (2016) The multiple testing issue in geographically weighted regression. Geographical Analysis, 48(3), 233-247.

Di Ciommo, F. How the Inaccessibility Index can improve transport planning and investment. International Transport Forum. Accessed at: https://www.itf-oecd.org/sites/default/files/docs/inaccessibility-index-transport-planning-investment_0.pdf

Dockerill, B. (2016) Liverpool Corporation and the origins of municipal social housing, 1842-1890. Transactions of the Historic Society of Lancashire and Cheshire, 165, pp.39-56.

DFT (2020) Gear Change: A Bold vision for Cycling and Walking, Department for Transport, London 
Dunning, R. \& Nurse, A. (2020) The surprising availability of cycling and walking infrastructure through COVID-19. Town Planning Review. 92 (2), 149-155

Dunning, R., Calafiore, A. \& Nurse, A. (2021) 20-minute neighbourhood or 15-minute city? Journal of the Town and Country Planning Association, 90, 5/6, 157-159

Edwards, M. M., \& Haines, A. (2007) Evaluating smart growth: Implications for small communities. Journal of planning education and research, 27(1), 49-64.

El-Geneidy, A. M., \& Levinson, D. M. (2006) Access to destinations: Development of accessibility measures. Technical Report, Minnesota Department of Transportation Research Services Section.

Ewing, R., \& Cervero, R. (2010) Travel and the built environment: A meta-analysis. Journal of the American planning association, 76(3), 265-294.

Feitelson, E. (2002) Introducing environmental equity dimensions into the sustainable transport discourse: issues and pitfalls. Transportation Research Part D: Transport and Environment, 7(2), 99-118.

Forsyth, A. (2015) What is a walkable place? The walkability debate in urban design. Urban Design International 20, no.4: 274-292.

Foth, N., Manaugh, K., \& El-Geneidy, A. M. (2013) Towards equitable transit: examining transit accessibility and social need in Toronto, Canada, 1996-2006. Journal of transport geography, 29, 1-10.

Fotheringham, A. S., Yang, W., \& Kang, W. (2017) Multiscale geographically weighted regression (MGWR). Annals of the American Association of Geographers, 107(6), 1247-1265.

Fotheringham, A. S., Brunsdon, C., \& Charlton, M. (2003) Geographically weighted regression: the analysis of spatially varying relationships. John Wiley \& Sons.

Frank, L.D., Hong, A. \& Ngo, V.D. (2021) Build It and They Will Cycle: Causal Evidence from the Downtown Vancouver Comox Greenway. Transport Policy.

Gaglione, F., Cottrill, C., \& Gargiulo, C. (2021) Urban services, pedestrian networks and behaviors to measure elderly accessibility. Transportation Research Part D: Transport and Environment, 90, 102687.

Gollini, I., Lu, B., Charlton, M., Brunsdon, C., \& Harris, P. (2013) GWmodel: an R package for exploring spatial heterogeneity using geographically weighted models. arXiv preprint arXiv:1306.0413.

Graells-Garrido E, Serra-Burriel F, Rowe F, Cucchietti FM, Reyes P (2021) A city of cities: Measuring how 15-minutes urban accessibility shapes human mobility in Barcelona. PLoS ONE 16(5): e0250080.

https://doi.org/10.1371/journal.pone.0250080

Grodach, C., Kamruzzaman, L. \& Harper, L. (2019) 20-Minute Neighbourhood - Living Locally Research. Victorian State Government. Accessed at: https://www.planning.vic.gov.au/_data/assets/pdf_file/0023/450275/Mambourin-ReportStaging-Community-Infrastructure.pdf.

Hansen, W. G. (1959) How accessibility shapes land use. Journal of the American Institute of planners, 25(2), 73-76.

Harris R \& Jarvis C (2014) Statistics for Geography and Environmental Science. Routledge.

Heinze, G., Wallisch, C., \& Dunkler, D. (2018) Variable selection-a review and recommendations for the practicing statistician. Biometrical journal, 60(3), 431-449.

Hu, L. (2019) Racial/ethnic differences in job accessibility effects: Explaining employment and commutes in the Los Angeles region. Transportation research part D: transport and environment, 76, pp.56-71. 
Iravani, H., \& Rao, V. (2020) The effects of New Urbanism on public health. Journal of Urban Design, 25(2), 218-235.

Johnson, B. (2020) A New Deal for Britain, accessed on 30th March 2021, accessed at: https://www.gov.uk/government/news/pm-a-new-deal-for-britain

Lambeth Council (2021) Railton Low Traffic Neighbourhood Stage One Monitoring Report, accessed at: https://beta.lambeth.gov.uk/streets-roads-transport/railton-low-traffic-neighbourhood-stage-one-monitoring-report

LCRCA (2020a) Liverpool City Region Combined Authority: Local Cycling and Walking Infrastructure Plan (LCWIP), accessed on 23rd February 2021, accessed at: https://www.liverpoolcityregion-ca.gov.uk/wp-content/uploads/LCR-LCWIPFinal.pdf

LCRCA (2020b) Liverpool City Region Combined Authority Becomes Founder Member of Inclusive Growth Network, Liverpool City Region Combined Authority, accessed on 23rd February 2021, Accessed at: https://www.liverpoolcityregionca.gov.uk/liverpool-city-region-combined-authority-becomes-founder-member-of-inclusive-growth-network/

Litman, T. (2002) Evaluating transportation equity. World Transport Policy \& Practice, 8(2), pp.50-65.

Marne, P. (2001) Whose public space was it anyway? Class, gender and ethnicity in the creation of the Sefton and Stanley Parks, Liverpool: 1858-1872, Social \& Cultural Geography, 2 (4), pp.421-443

Martens, K. (2016) Transport justice: Designing fair transportation systems. Routledge.

Mattioli, G. (2017) "Forced car ownership" in the UK and Germany: socio-spatial patterns and potential economic stress impacts. Social Inclusion, 5(4), 147-160.

Mattioli, G., Roberts, C., Steinberger, J. K., \& Brown, A. (2020) The political economy of car dependence: A systems of provision approach. Energy Research \& Social Science, 66, 101486.

Markley, S. (2018) Suburban gentrification? Examining the geographies

of New Urbanism in Atlanta's inner suburbs, Urban Geography, 39:4, 606-630, DOI:

$10.1080 / 02723638.2017 .1381534$

Mennis J., (2006) Mapping the Results of Geographically Weighted Regression, The Cartographic Journal, 43:2, 171-179

Morgan, M., Young, M., Lovelace, R., \& Hama, L. (2019) OpenTripPlanner for R. Journal of Open Source Software, 4(44), 1926.

Mould, O. (2014) Tactical urbanism: The new vernacular of the creative city. Geography compass, 8(8), 529-539.

Munck, R. (ed.) (2003) Reinventing the City? Liverpool in Comparative Perspective, Liverpool University Press, UK

Nieuwenhuijsen, M., \& Khreis, H. (2019) Urban and transport planning, environment and health. In Integrating human health into urban and transport planning (pp. 3-16). Springer.

McNeil, N. (2011) Bikeability and the 20-min neighborhood: How infrastructure and destinations influence bicycle accessibility. Transportation research record, 2247(1), 53-63.Nurse, A. \& Dunning, R., (2020). Is COVID-19 a turning point for active travel in cities?. Cities \& Health, pp.1-3.

O’ Gorman S. \& Dillon-Robinson R., (2021) 20 Minute Neighbourhoods in a Scottish Context, Accessed at: https://era.ed.ac.uk/bitstream/handle/1842/37524/CXC\%20-

$\% 2020 \% 20$ minute $\% 20$ neighbourhoods\%20in\%20a\%20Scottish\%20context\%20March\%202021.pdf?sequence=3\&isAllowed $=\mathrm{y}$ 
Oshan, T. M., Li, Z., Kang, W., Wolf, L. J., \& Fotheringham, A. S. (2019) mgwr: A Python implementation of multiscale geographically weighted regression for investigating process spatial heterogeneity and scale. ISPRS International Journal of Geo-Information, 8(6), 269.

Papa, E. (2020) Transport Access Manual: A Guide for Measuring Connection between People and Places. Committee of the Transport Access Manual, University of Sydney.

Pan, Q., Jin, Z. \& Liu, X. (2020) Measuring the effects of job competition and matching on employment accessibility. Transportation Research Part D: Transport and Environment, 87, p.102535.

Park, Y., \& Guldmann, J. M. (2020) Understanding disparities in community green accessibility under alternative green measures: A metropolitan-wide analysis of Columbus, Ohio, and Atlanta, Georgia. Landscape and Urban Planning, 200, 103806 .

Parkinson, M. (2020) Liverpool: Beyond the brink, Liverpool University Press

Pereira, R. H., Schwanen, T., \& Banister, D. (2017). Distributive justice and equity in transportation. Transport reviews, 37(2), 170-191.

Pozoukidou, G. \& Chatziyiannaki, Z. (2021) 15-Minute City: Decomposing the New Urban Planning Eutopia. Sustainability, 13(2), p.928.

Power, A., (2012) Social inequality, disadvantaged neighbourhoods and transport deprivation: an assessment of the historical influence of housing policies. Journal of Transport Geography, 21, pp.39-48.

Proffitt, D. G., Bartholomew, K., Ewing, R., \& Miller, H. J. (2019) Accessibility planning in American metropolitan areas: Are we there yet?. Urban Studies, 56(1), 167-192.

Rae, A. (2012) Spatially concentrated deprivation in England: An empirical assessment, Regional Studies, 46 (9), pp.11831199

Reid, C., (2020) Anne Hidalgo Reelected as Mayor of Paris Vowing to Remove Cars and Boost Bicycling and Walking. Accessed at: https://www.forbes.com/sites/carltonreid/2020/06/28/anne-hidalgo-reelected-as-mayor-of-paris-vowing-toremove-cars-and-boost-bicycling-and-walking/?sh=ba645d11c852 (accessed on 20 August 2021).

Seya, H. (2020) Global and local indicators of spatial associations. In Spatial Analysis Using Big Data (pp. 33-56). Academic Press.

Shashank, A., \& Schuurman, N. (2019) Unpacking walkability indices and their inherent assumptions. Health \& place, 55, 145-154.

Stanley, J., \& Davis, S. (2015) Connecting neighbourhoods: the 20 minute city. Policy Paper.

Sustrans (2020), What is a 20-minute neighbourhood?, Accessed at: https://www.sustrans.org.uk/our-blog/get-active/2020/inyour-community/what-is-a-20-minute-neighbourhood

Sykes, O., Brown, J., Cocks, M., Shaw, D. \& Couch, C. (2013) A City Profile of Liverpool, Cities, 35, pp.299-318

Yin, C., He, Q., Liu, Y., Chen, W., \& Gao, Y. (2018) Inequality of public health and its role in spatial accessibility to medical facilities in China. Applied Geography, 92, 50-62.

Yu, H., Fotheringham, A. S., Li, Z., Oshan, T., Kang, W., \& Wolf, L. J. (2020) Inference in multiscale geographically weighted regression. Geographical Analysis, 52(1), 87-106.

Weng, M., Ding, N., Li, J., Jin, X., Xiao, H., He, Z., \& Su, S. (2019) The 15-minute walkable neighborhoods: Measurement, social inequalities and implications for building healthy communities in urban China. Journal of Transport \& Health, 13, 259273. 
Wilson, K., (2021) Can this App Tell You If You Live in a 15 Minute Neighbourhood? Accessed at: https://usa.streetsblog.org/2020/10/21/can-this-app-tell-you-if-you-live-in-a-15-minute-neighborhood/

\section{Appendix A}

Maps of the standardized distribution of the independent variables (A), and local coefficients of basic GWR (B) and

Multiscale GWR (MGWR) (C) - Dependent Variable: Standardized Access Score. Grey areas are non-significant (95\%

Significance Level).

1. Estimated Population 2019

A

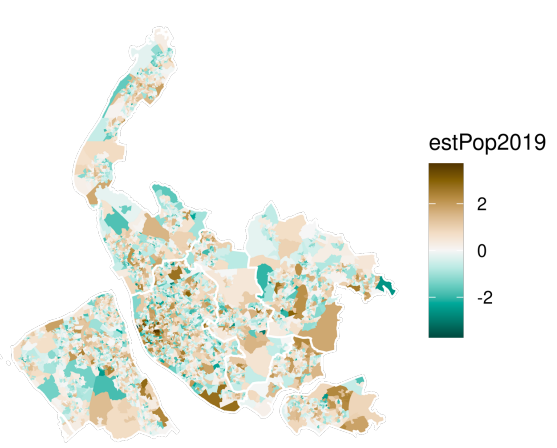

B

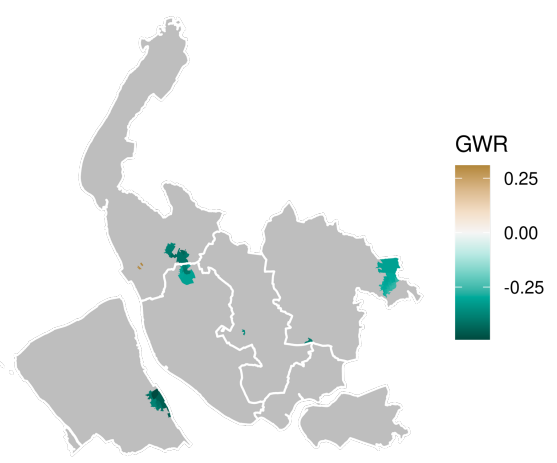

C

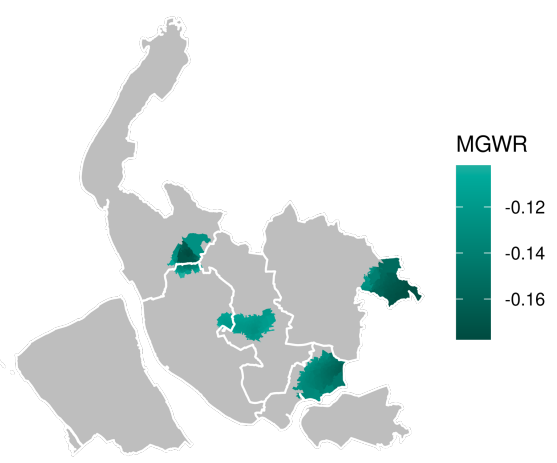


2. Black Population

A

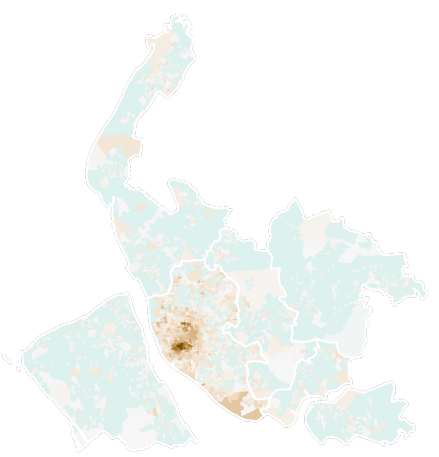

B

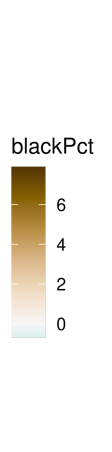

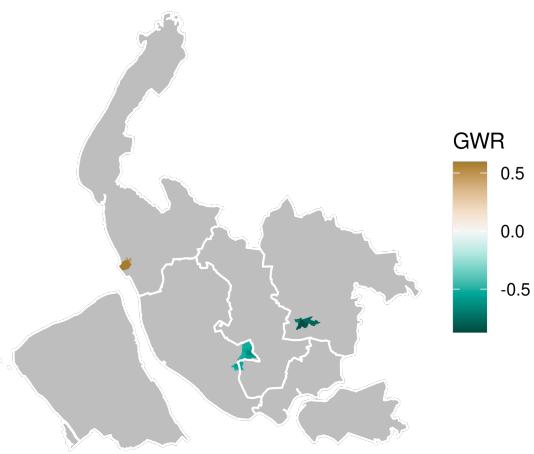

C

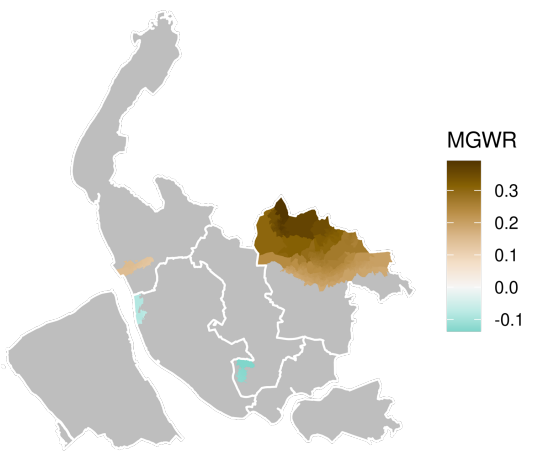

3. Multiple Ethnicity

A

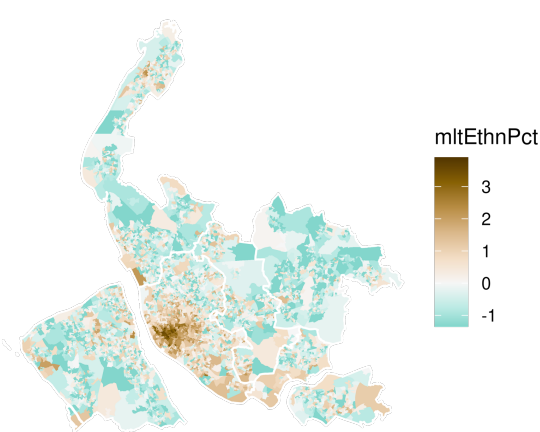

B

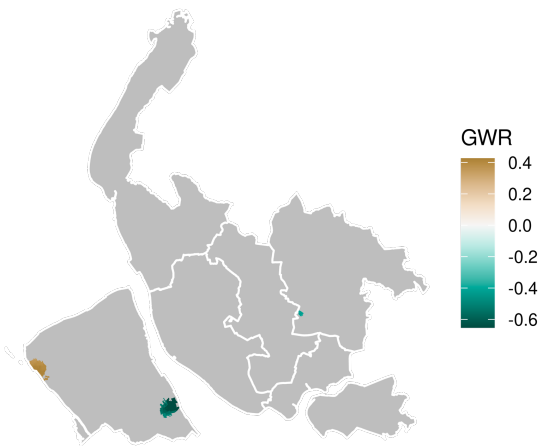

C

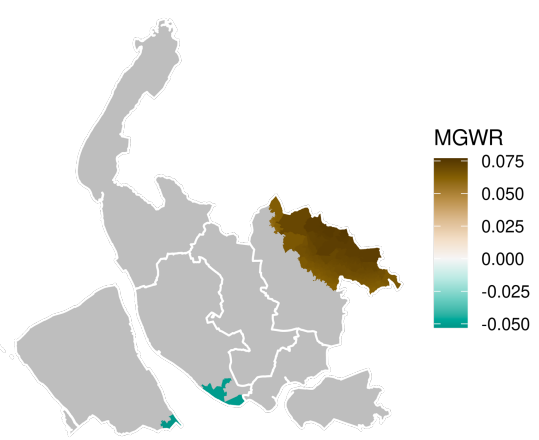


4. Other Ethnicity

A

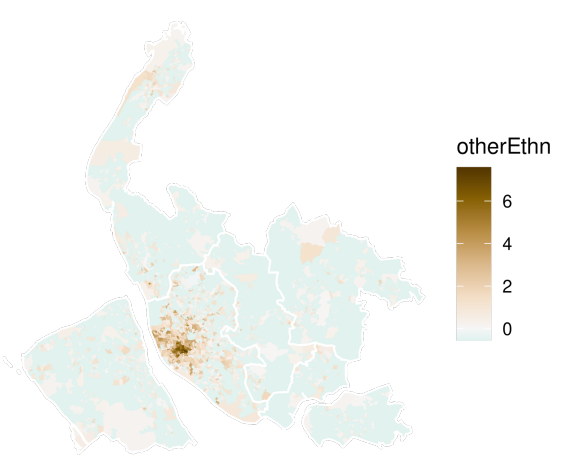

B

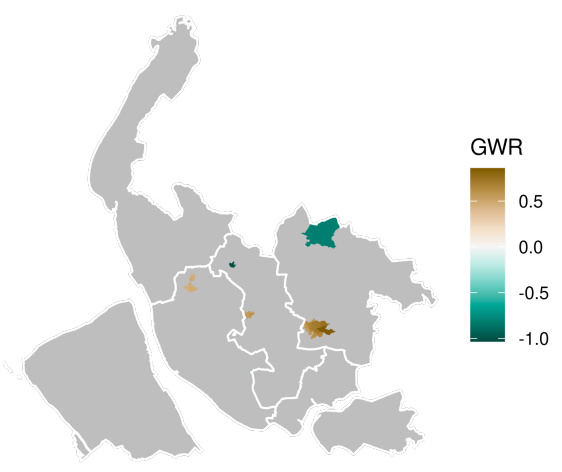

C

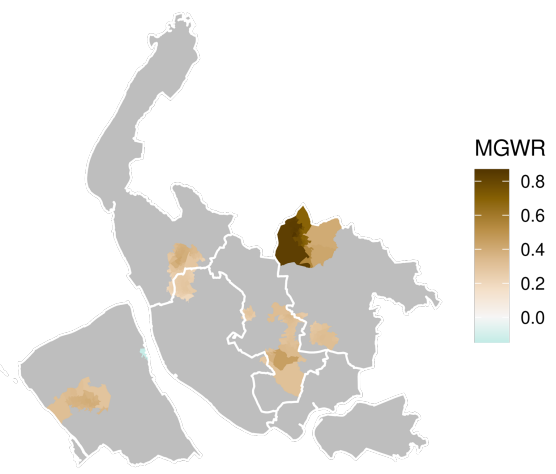

5. Car Ownership

A

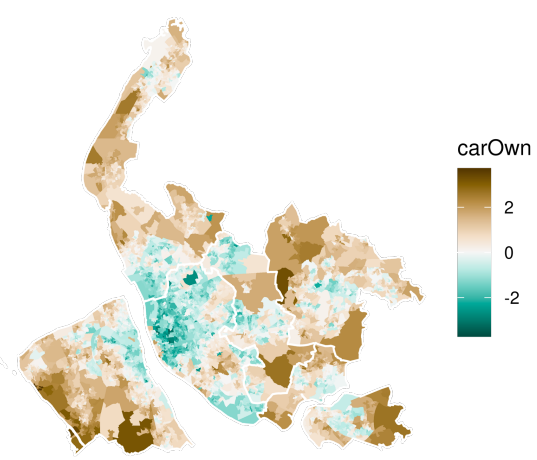

B

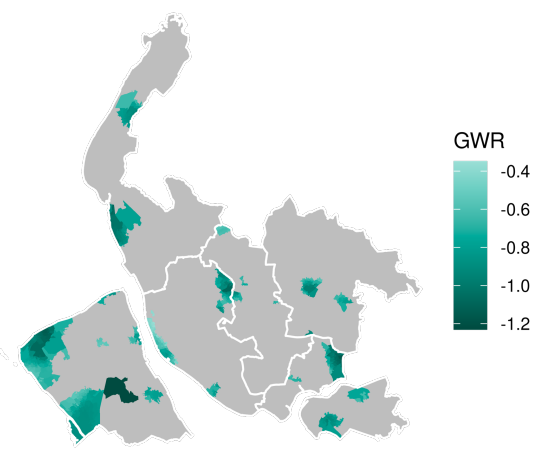

C

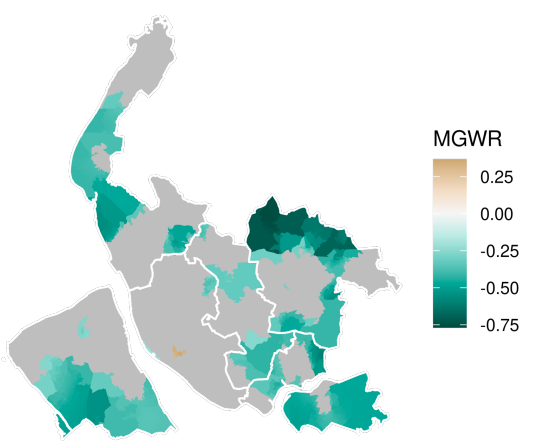

6. IMD Education Score

A

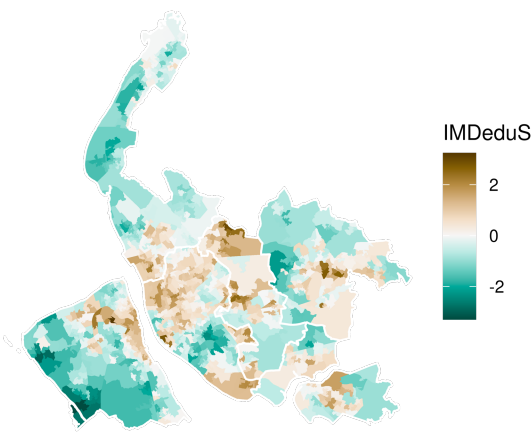

B

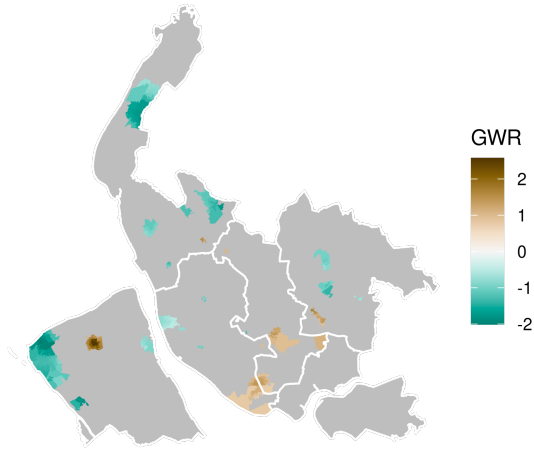

C

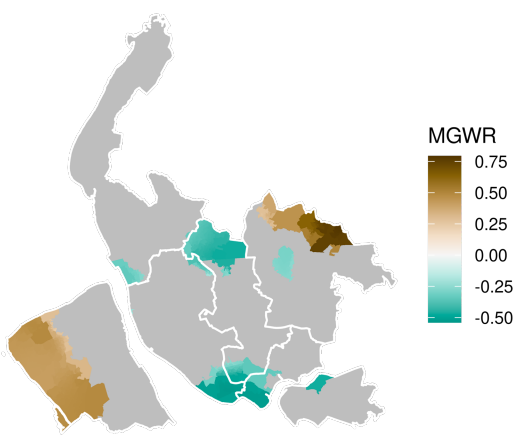


7. House Prices (5 years average)

A

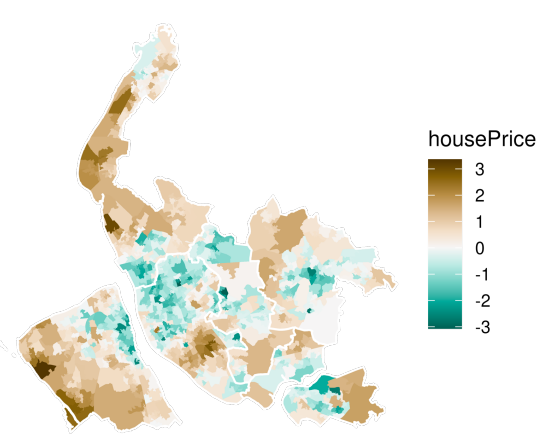

8. Traffic and Injuries

A

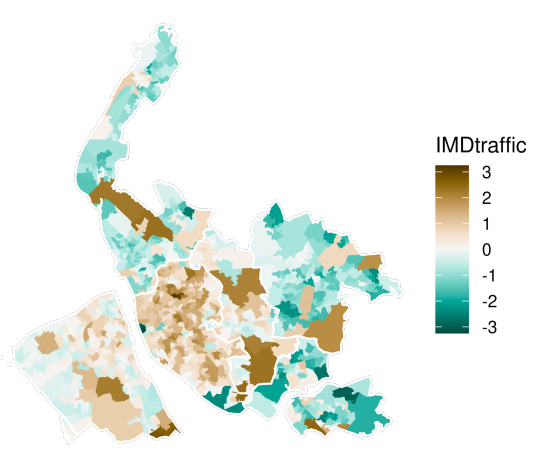

B

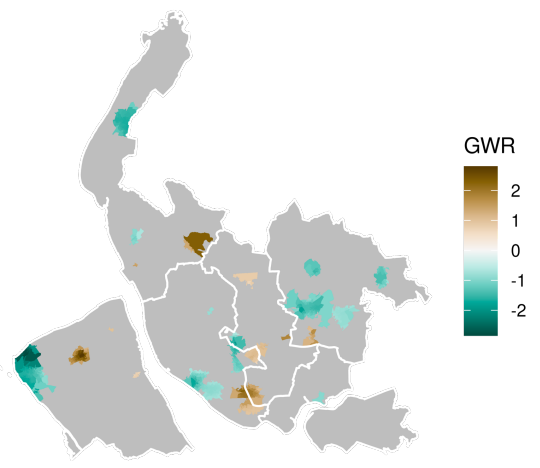

C

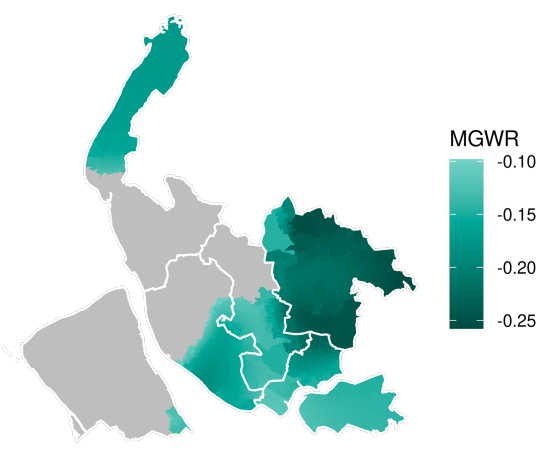

B

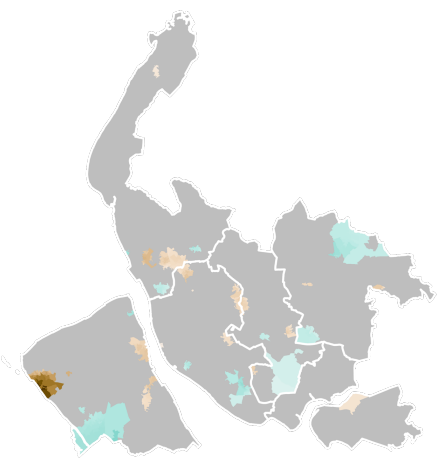

C

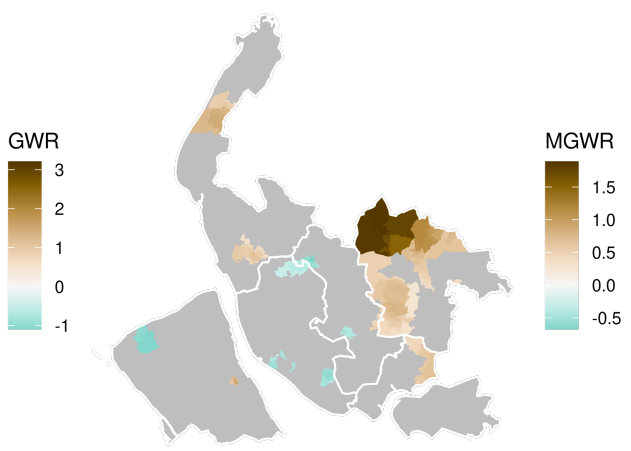

9. Air Quality Deprivation

A

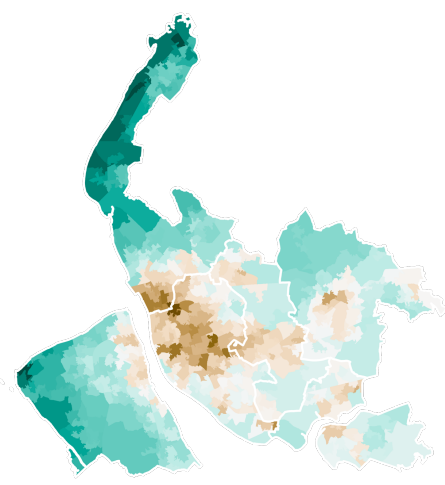

B

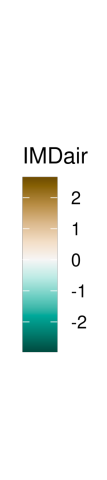

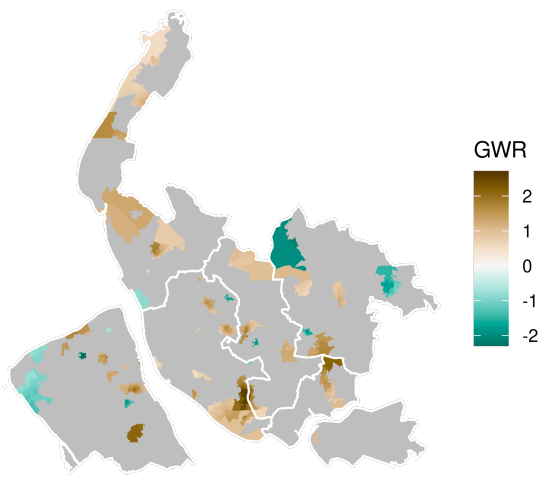

C

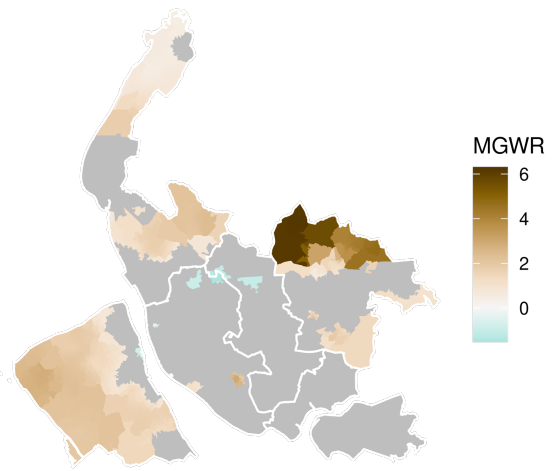


